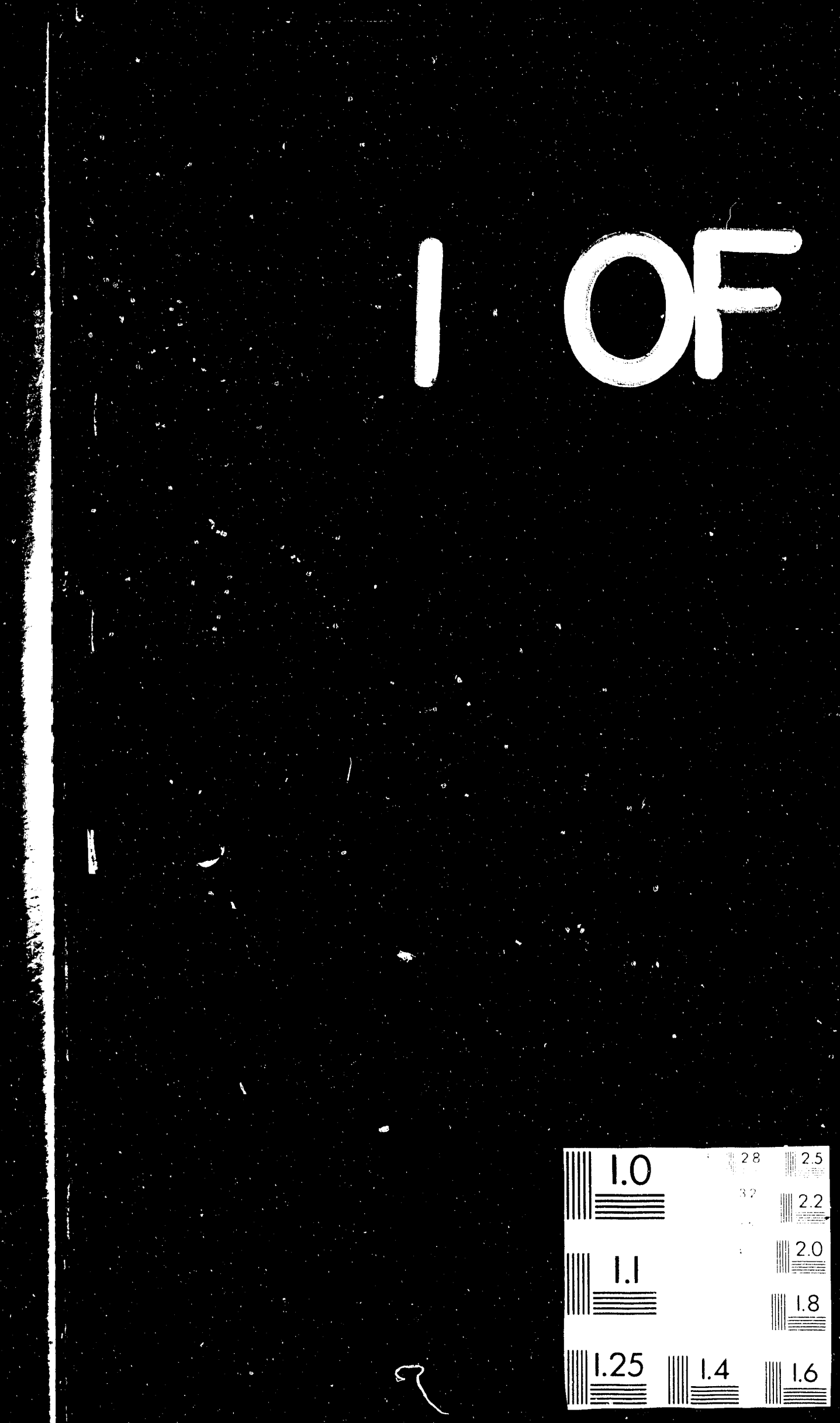




\title{
Optimisation Studies For Scintillator Plate Calorimeter
}

\author{
P.K..Job, R.Blatir and L.Price \\ High Energy Physics Division \\ Argome Nalional Lals
}

\section{Introduction}

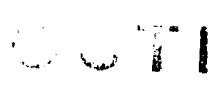

This note is the prelininary report of the results of optimisation studies at $A N L$ for the proposed scintillator plate calorimeter for $\mathrm{SSC}^{(1)}$. In this note we have tried to optimise some of the basic parameters for the calorimeter with the arailable simulation tools at ANL. These simulation studies were carried out using ECis.t and CEANT 3.11 with (iHEISHA 7 implementation) on ANL CRAY XMP 4 computer. The various input parameters for CEANT and ECiS were optimised and valirlated using the arailable test beam data. The codes thus validated wore used to calculate: some of the basic parameters for the scintillator plate calorimeter for SSC' With dirferent absorber materjals.

\section{Validation of GEANT and EGS with test beam data}

Test beam data from four different experiments were compared with the resulls of full shower simulation using CEEANT and ECiS. Fou benchmarks have been chosen so far to compare the test beam results with the simulation.

The benchmarks chosen for this study are

a.ZEUS F(AI Prototipe Measurements ${ }^{(2)}$.

b. Bathow's study of EM showers in Lead ${ }^{(3)}$.

c.WA TS (ZEUS) Experiments. ('atanesi el al(4).

d.Iron Scintillator ('alorimeler Experiment. Bollini at al(i). 


\section{DISCLAIMER}

This report was prepared as an account of work sponsored by an agency of the United States Government. Neither the United States Government nor any agency thereof, nor any of their employees, makes any warranty, express or implied, or assumes any legal liability or responsibility for the accuracy, completeness, or usefulness of any information, apparatus, product, or process disclosed, or represents that its use would not infringe privately owned rights. Reference herein to any specific commercial product, process, or service by trade name, trademark, manufacturer, or otherwise does not necessarily constitute or imply its endorsement, recommendation, or favoring by the United States Government or any agency thereof. Tlie views and opinions of authors expressed herein do not necessarily state or reflect those of the United States Government or any agency thereof. 


\section{2.a ZEUS FCAL Prototype Measurements}

The ZEUS FCAL Prototype modules consist of $3.3 \mathrm{~mm}$ thick Depleted Iranimm and $2.6 \mathrm{~mm}$ scintillator plates. Fig.1 gives the experimenlal set up. The Depleted Uranium plates are clad in $0.2 \mathrm{~mm}$ of Stainless Steel. Each morlule consists of fom: $20 \% 20^{2} \mathrm{~cm}$ towers and is segmented longiludinally into an Electromagnetic $\left(1 \lambda_{i n}\right)$ Iadronic I $\left(3 \lambda_{i n t}\right)$ and Hadronic II $\left(3 \lambda_{i n t}\right)$ sections. This geometry is chosent 10 optimise the energy cuts used in GEANT and to validate the simulation results.

The major kinetic energy cuts used in CEANT are for hachonselectrons. neutrons and muons, and also for electron,muon and hadron bremsstralılung and for delta ray production by electrons and muons. The sensitivity of the shower parameters to these energy cuts is carefully evaluated. The Shower profiles and the energy depositions in the rarious modules of the calorimeter are estimated for 10 Ciel pions for which detailed ZEUS measurements are arailable(2). The energy cuts considered are $10 \mathrm{MeV} .5 \mathrm{MeV}, 1 \mathrm{MeV}, 300 \mathrm{Kcl}$ and $100 \mathrm{KeV}$. All the CiEANT cuts are sot to the same value for both active and absorber material.

Fig.2 gives the total energy deposition in the scintillator plates as a function of all the energy cuts. It can be seen that below the energy cut of $1 \mathrm{MeV}$. the calculated total energy deposition is not very sensitive to the cuts. But between the energy range of $1 \mathrm{MeV}$ to $10 \mathrm{MeV}$ there is a $20 \%$ change in calculated energy deposition. Fig.3 gives the same result as a function of nentron energy cut setting all of her cuts as $300 \mathrm{KeV}$. This also confums the abore conclusion. It can also be inferred that roughly 50\% of the error in the GEANT estimation of energy deposition due to higher energy cuts is caused by neutrons in the energy range of $1 \mathrm{Mel}$ to $10 \mathrm{Mr}$ :

The longitudinal shower profiles corresponding to these energ! cuts are giren in fig.t and ta. The shower profiles are normalised to the total encrgy drposition in the scintillator. The plots show that the differential energy deposition in llw scintillator layers is sensitive to the energy cuts cren below 1 Mel. Table I gires the comparison of the calculated differential energy deposition in EM('.MIIC'I and

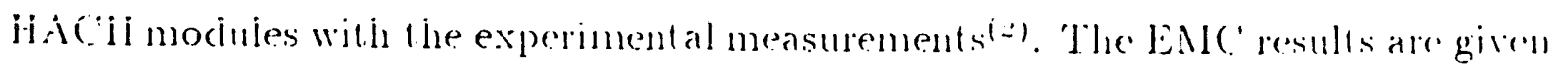


for different encrgy cuts. There is a $5 \%$ change in ENC' energy cleposition when the cuts increased from $300 \mathrm{kel}$ to $1 \mathrm{MeV}$. The result shows that at the energy cul of $300 \mathrm{KeV}$ the the agrement between the calculation and the measurement is quile good. We therefore chose $300 \mathrm{KeV}$ as the energy cuts for all subsequent. (iEANT calculations.

\section{2.b. Bathow's Measurements in lead}

The experimental geometry used by Bathow et al is simulated by ECiS code as a rectangular lead block of $20 \mathrm{~cm}^{*} 20 \mathrm{~cm}^{2}$ transverse and $22.5 \mathrm{~cm}$ (40 radiation lengths) longitudinal dimensions. Fig.5 gives a sketch of the experimental geometry: In the longitudinal direction the geometry was dirided into to regions (one radiation length each). The energy of the incident beam was 6 GeV with nomal incidence on the lead block. The energy deposition was scored for each of these regions. In the transwerse direction the energy deposition was scored in 50 bins from the beam position to $5 \mathrm{~cm}$ ( 1 Moliere radii). The transverse distributions were obtained at two different shower depths, at 5 and 12 radiation lengths. The number of events simulated were 1000 and the error in energy deposition in each of the longitulimal and transrerse bins were evaluated by a separate program. The statistical error in energy deposition is $1.5 \%$ at shower maximum and $6 \%$ at shower tail. The ('PI time utilisation was $0.2 \mathrm{sec} /$ Ciel/erent on C'ray.

The results of this study are given in figs 6,7 and 8 . Fig 6 gives the longitudinal shower profile from the simulation plot ted along with the experimental profile. The agreement is good. Fig $T$ and $\&$ gives the transwerse shower profiles at two diffremt shower depths, at 5 and 12 radiation lengths. A reasonable number of tracks coukl not be counted beyond 4 Moliere radii. It has also been observed that the transwerse profiles are very sensitive to the ECiS cut parameters.

\section{2.c.WA 78 DU-Scintillator Calorimeter}

The calorimcter consists of $10 \mathrm{~mm}$ depleted uranium and $5 \mathrm{~mm}$ plastic Sintillatur layers. Fig.9 gives a schematic diagram of the experimental set up. The upstream 
uranium part is made of $t 5$ elements consisting of a $D I$ ' sheet followed by a scintillator sheet. The Uranium is enclosed in $1 \mathrm{~mm}$ steel. The clowstream iron part consists of 58 iron and scintillator elements. The longitudinal shower profiles were measured for Pions in the energy range of 5 to 210 GeV. This geometry is simulated by CEANT. The tail region of iron scintillator calorimeter has not been simulated in this study. Longitudinal shower profiles are obtained for 5, 10, 20, 40 and 1:35) Ciel pions. One thousand events are simulated for each case. The earlicr optimiscel energy cuts of $300 \mathrm{Kiel}$ is used for these calculations. The statistical error at each point is less than $4 \%$. The C'PU time utilization is $0.1 \mathrm{sec} /$ Ciel /erent on ('ray.

The results are given in Figs 10.11.12.13 and 1-. It can be seen that the longitudinal shower profiles from GEANT simulation is in reasonably good agrement. with the experimental data. GEANT tends to orerestimate the encrgy cleposition towards the shower tail. The transrerse profiles were not arailable for comparison.

\section{2.d.Iron-Scintillator Calorimeter}

This calorimeter consists of iron plates of different thicknesses arranged in a perjorlic 6-3-6 cm structure. Fig.15 gives the schematic diagram of the experimental set up). Each plate is followed by a plastic scintillator of thickness of $7 \mathrm{~mm}$. There were 22 such planes corresponding to a total cicpth of $120 \mathrm{~cm}$ of Iron. The longitudinal and transverse shower profiles were measured for electrons and pions of 20.10 and 8 (; Ciev.

This configuration is simulated by. CIEANT and ECSS. Shower profiles are gonerated for -10 and $\$ 6$ GeV pions using GEANT. One thonsatid events are simulaterl for each case. The energy cuts used are 300 KeV. The statistical error on each point is less than $5 \%$. The C'PU time utilisation is $0.1 \mathrm{sec} /$ GeV/erent. The resulls aw given in figs 16 and 17 . The agrement is very gool.

Inorder to compare the two programs. the EN shower profiles are gemerated

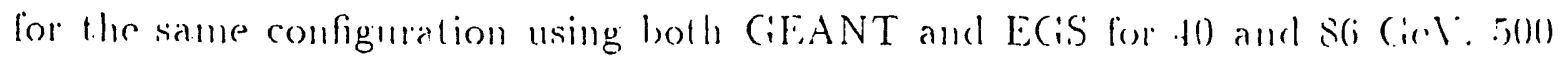

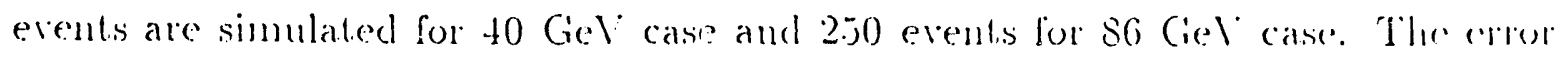
is less than 3\%. The CPU time ulilisation for CEANT EM shower simmialion 
is $0.2 \mathrm{sec} /$ GeV $/$ erent and for EGiS $~ 0.3 \mathrm{sec} /$ Ger/erent. The results are giren in Figs Is and 1\%. The agreement is good except at the shower tail where lle simulated data are high, this time for EM showers. It can also be noticed that in this case the agrement between EGS and CEANT is excellent.

Our initial eraluation of the results of this study so far is that to first order. CEANT and ECSS reasonably reproduce test beam profiles and integral energy deposition. For hadronic showers, (IEANT some times give longitudinal profiles that are high in the tail region (after about 3 interaction lengths). For clectromagnetic showers, the comparison with the clata of Bollini.et al.. shows ECiS giving high results after about 20 radiation lengths. For both hadronic and electromagnelic showers, it would be desirable to have more comparisons with different data sets. in order to separate the shortcomings of the simulations from those of the clata. Careful benchmarking is also desirable for resolution and e/h results. Relatively few transverse experimental profiles have get been found for comparison.

\section{Configurations Considered For SSC Calorimeter}

The purpose of this study is to evaluate some of the basic paranteters for a scintillator plate calorimeter for SSC: Different absorber materials were considered from the point of view of the compensation, resolution and cost. The shower dimensions are evaluated to determine the optimum tower size and the longitudinal shower containment. Response plots are generated to estimate the resolution.

Three configurations are considered in this study:

1. Depleted Lranium- Scintillator

2. Leacl- Scinlillator

3. Iron- Scintillator

In all cases approximately compensating ratio of thicknesses of alsomber and active media are chosen based on the previous studies (ti.i.8." ). The saliend fealures of these configurations are giren in Table II. In these preliminary estimales rlfert of cladding has not been simulated. The earlier optimised (iEANT and E(is'(1') eneigy cuts are used. 
The the parameters considered for optimisation are
a. The C'alorimeter Depth
b. Lateral Segmentation
c. Sampling Thickness
d. e/h Ratio
e. Resolution

\section{3.a Calorimeter Depth}

The depth of the calorimeter in torms of the nuclear interaction length of the conliguration and its effects on the shower containment and resolution have been studied. This study is carried out for all the configurations and for 10 Cicl: and 100 (ie: pions. The beam is incident in the $\mathrm{Z}$ direction at the midelle of the tower at nomal inciclence.

Fig 20 gires the differential energy deposition in the scintillator plates in the DUISC'IN configuration for 10 Ciel piuns and electrons and Fig 21 gives the integral energy deposition for the same geometry. The arerage of 500 electromagnetic and 1000 hadronic events are plotted. The Figures show that nearly gs\% of the Electromagnetic Shower encrgy is contained by a thickness of 20 racliation lengths whereas only 20\% of the IJachonic Shower energy is contained by the same thickness. This study is extended to determine the tolal thickness of the calorinue whe wich can contain a 10/100 Giel hadronic shower. Fig 22 gires the result of this study for the DU-SCIN geometry for both 10 and 100 Gel pions. The shower contaimment integrated over the radius is plotted as a function of the calorimeter depth in units of nuclear interaction length $\left(\lambda_{i n t}\right)$. It can be seen that for both the cases a $\left(i, t_{m}\right.$ deep calorimeter is sufficient to contain almost 99\% of the liadronic shower energe. A $5 x_{\text {int }}$ thick calorimeter can contain only $92 \%$ of the 100 Cicl and $95 \%$ of 10 Cirl. hadronic shower.

Fig 2:3 gives the same result for the three configuations. Almost 9s\% of lhe hadronic shower is contained by the calorincter with a hickness of $6 \lambda_{i n t}$ in all the three cases. In the DUISCIN case where the ratio of the radiation lenglh to 
the nuclear interaction length is the smallest and the sampling is funce in torms of racliation length, the shower is dense and spacially compressed in terms of nuclear interaction length. Therefore the shower containment is the best for DU-SC'IN case. This phenomenon is more evident in figure 23.a where the shown containment. is plotted in term of calorimeter depth in centimeters. The important practical implication of this result is that one can afford to save on thickness in DII-SCIN case lor a fully contained calorimeter.

Fig $2 t$ gives the change in hadronic resolution, $(\sigma / E)_{\text {inf }}-(\sigma / E)_{1}$, as a function of calorimeter thickness (t) at 10 and $100 \mathrm{GeV}$ for DU-SC'IN case. The cliange is plotted with respect to a calorimeter of infinite thickness $\left(15 \lambda_{\text {int }}\right)$ on a log scale. The plot fits into an approximate straight line for both 10 and 100 Ciel cases. $A$ $6 \lambda_{\text {int }}$ thick calorimeter las a resolution which is $3 \%$ worse than the infunte case for 100 Ciel pions and for a $5 \lambda_{\text {int }}$ calorimeter it is worse by 15\%. Fig 25 gives the resull. of the same study for the three configurations for 10 Ciev pions only. The change in resolution is most sensitive to calorimeter depth in the case of DI-SCIN case with one radiation length sampling and least sensitive in the case of Pl-SC.'IN where the sampling thickness is two racliation lengtlis.

Both these studies confirm that from the point of view of shower containment and resolution the minimum thickness of the calorimeter must be around 6 interaction lengths for all the three configurations and a thicker calorimeter only improres these parameters marginally:

\section{3.b Lateral Segmentation}

The laieral dimensions of the shower profiles are cletermined accurately to estimale the optimum tower size for the calorimeter. These calculations are clone by CEANT binning the lateral energy deposition. Simulations are carried oul for all three configurations for 10 Ger and 100 Ciel pions. They are also reprated for the proposed projective geometry for 10 Cicl case. Fig 26 gives the sclicmatic diagram of the simulated projective tower. The calorimeter is at a radius of $2 m$ from thr 
interaction point. The longitudinal dinnension of the towers is $S \lambda_{\text {int }}$ and the onter surface is calculated accordingly:

Fig 27 gives the results of this study for DU-SCIN geometry lor 10 Ciel and 100 Ciel pions. A $10^{*} 10 \mathrm{~cm}^{2}$ tower contains only $50 \%$ of the 100 GeV shower whereas a $20^{*} 20 \mathrm{~cm}^{2}$ tower conlains more than $75 \%$ of the 100 GeV shower. For 10 Cicl pions, results are also plotted for both straight and projective towers. For a $20 " 20$ $\mathrm{cm}^{2}$ projective tower the shower containment improves by $5 \%$. The projective tower improves the shower containment by $15 \%$ in the case of $10^{* *} 10 \mathrm{~cm}^{2}$ tower. Fig 30 gires the same result for all the three configurations for 10 Gel pions only. The lateral shower containnent by towers of Pb-SCIN configuration for 10 GieV pions is rery similar to that of DUT-SCIN towers. The showers in the FE-SCIN towers, which contains thick iron absorber plates, are fatter in lateral dimensions and recuires bigger towers to contain them.

\section{3.c Sampling Thickness}

The effect of varying the sampling thickness on the resolution and compensation of the calorimeter is studied using (EEANT in the DU-SCIN configmation for 10 Ciel pions. The sampling thickness is raried from 1 to 6 radiation lengths. The total chepth of the calorimeter is $6 \lambda_{\text {int }}$ for these calculations.

The change in hadronic and electromagnetic resolntion with respect to one radiation length sampling configuration, $(\sigma / E)_{n \times 0}-(\sigma / E)_{1 \times 0}$. is plotted as a function of the squareroot of the sampling thickness in Fig 29. The results are given lor both 10 Ciel hadrons and electrons. The Electromagnetic resolution is calculated by ECiS and the hadronic resolution by GENT. The results show that the change in resolution obeys an approximate squareroot law in terms of sampling thickness for both Electromagnetic and hachonic showers upto a sampling thickness of four racliation lengths. Two radialion length sampling worsens the resolution by 0 lo ' $/ 1$ in the case of 10 Ciel hadrons and electrons.

Fig 30 gives 1 lee $\mathrm{c} / \mathrm{h}$ ratio calculated by (iEANT and ECiS as a function of sam-

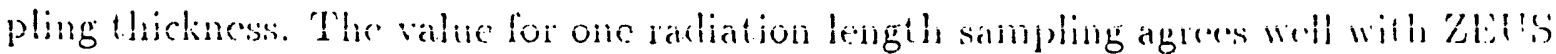


measurements(2). But CiEANT estimales of e/h ratio remained insonsitive to rarying sampling thickness when the ratio of thicknesses of the absorber material to the active material remained same. We feel that this aspect needs furthor investigation. We are in the process of implementing CALOR cocle("1) at $A N L$ which is supposcd to treat low energy neutron transport better. we have planned an independent. estimation of all these parancters using C'ALOR.

\section{3.d e/h ratio}

The e/h ratio for all the three configurations are eraluated using CEANT and ECiS and compared with the exprimental results. Table IIl gives the comparison of the results of the calculated $e / h$ ratio for the three configurations with the published experimental results (2)(2)(1;). The agreement is surprisingly very good. The lower measured value for the ZEUS case could be due to the fact that the clarlding is nol been simulated which is in the right direction(12). The agreement of e/h ratio with the measurements in this section and in section 3.c may be fortuous. In can be due to the fact that in the configurations considered. the low energy neutron flux is a slowly wrying function of chergy and space aud the CilleISIIA cross sections lor luw energy neutron transport cloes not introrluce a serious error in the calculated integral energy deposition. Howerer a more detailed e/h evaluation has been phanned wilh ('ALOR cocle system which treats the low energy neutron transport $\leq 20 \mathrm{NoV}$ in 100 lethargy groups and the lethargy group cross sections are obtained by Mux weighting the measured point cross section clata.

\section{3.e Resolution}

Electromagnetic and hadronic resolutions are calculated using ECis and (iEANT and compared with the arailable test beam results. These calculations are done for all the three configurations. The cnerg! range considered is only 5-10 (ict:

ECis results for the DU-SCIN configuration for 5 and 10 Cicl electrons are giren in Fig.31 and 32. The respons? plot for 250 events are given for both the anses. 
The arerage and the width at hall maximum are estimated by a $2 \sigma$ fit. The calculated resolutions $(\sigma / \sqrt{E})$ from the fit are given in Table IV along with the ZEUS measurements ${ }^{(13)}$. The agreement between EGS results and ZEUS measurements for elatrons is rery good for both the energies. The response plot for PB-SCIN case is given in Fig 3:3 for 10 CeV electrons. The fitted resolution is given in Table IV. The experimental result ${ }^{(9)}$ is also given for comparison. The agreement is good. It appears that ECiS is able to predict the electromagnetic resolution rery woll for most of the cases although more benchmarking at higher energies for different configurations is clesirable.

CEANT results for the DU-SCIN configuration for both 5 and 10 Giel pions are given in Figs $3 t$ and 35. The response plot for thousand events are giress. The calculated resolution $(\sigma / \sqrt{E})$ from the fit is given in Table $1 V$ along with the measurements ${ }^{(t 3)}$. It can seen that the agreement is satisfactory although the simulation clata is higher than the measurements. The response plot for PB-SCIN configuration is given in Fig.36 and the fitted resolution in Table 11. The experimental clata $^{(2)}$ is given for comparison. The agreement in this case is bad clue to some reason we are unable to determine. The response plat for the ('DF central hadron calorimeter configuration (FE-SCIN) is given in Fig.37 and 38. The fitter resolutions $(\sigma / \sqrt{E})$ are given in Table IV for 10 and 2:5 CieV along wilh the ('DF measurements ${ }^{(1)}$. The agreement in this case is rery good.

For all the three configurations estimates of resolution at higher encrgics (in lhe range of 50-100 (iel) are needed. Alternate configurations are also to be considered. At present these programs are impeded due to C'PU time considerations. Typirally. a 10 Ciel run for 1000 events take roughly an hour on ('RAY XMP 1 for all the three configurations. The capability of ('ALOR in predicting the resolution is also under investigation.

\section{Conclusions}

The main conclusions of this study can be summarised as follows. 
CEANT and ECiS reasonably reproduce test beam profiles. Bul more benchmarking is necessary at higher energies as far as resolution, lateral distribution and e/h ratios are concerned.

The calorimeter clepth of $6 \lambda_{i n t}$ is minimum for the full shower containment and a thicker calorimeter only marginally improves the shower contaimment alid resolution. In the case DIT-SCIN calorimeters, one can possibly have a saving on thickness.

A $10^{*} 10 \mathrm{~cm}^{2}$ projective tower can contain $75 \%$ of the $10 \mathrm{GeV}$ shower. This agrens well with ZEUS measurements.

The penalty paid for two radiation length sampling is of the order of $(;$ to $5 \%$ on hachonic and electromagnetic resolution.

The aspect of compensation in terms of two radiation length sampling is to be carefully looked into, preferably by a cocle like ('ALOR which simulates low energy' neutron transport more accurately.

\section{ACKNOWLEDGEMENTS}

The aullors wish acknowledge the raluable suggestions giren by Dr... Proudliool and Dr.T.Kirk during the progress of this work. 


\section{REFERENCES}

[1] SSC Subsystem Proposal, ANL-IIEP-TR-S9-111

[2] E.Ros aurl T.Tsurugai, ZEUS Note SS-0S6(19S8)

[3] Ci.Bathow, et. al.,Nucl.Phy.:B20(1970).

[.1] M.Ci.Calanesi,et. al.Nucl.Inst.Meth.A260(19ST)4:3-54.

[5] D.Bollini, et al.,Nucl.Inst..Meth.171(1980)2:3i-24t.

[6] H.Bruckmann, et a],DESY SG-115(1986).

[7] A.Furtjes, et al,ZEUS' S!-69(1989).

[8] R.Wigmans, Nucl.Inst.Mcth.A25.9(195T).

[9] E.Bernadi,et a],Nucl.Inst.Neth.A262(19ST)229).

[10] P.K..Job, et al..Nucl.Instr.Meth.A2T1(198S) 4.42.

[11] T.Ciabriel, et al. C'ALOR, RSIC: Report C:C'C'-1TS

[12] II.Bruckimann, et al., DESY ST-061(1!ST).

[1:3] A.Furtjes. et al..ZE[SS S9-69(19s9).

[1.1] S.Bertolucci, et al. Nucl.Inst.Meth.A267(1988):301 
TXIBIE 1

('omparison wilh ZEUS FC:AL Neasurements

\begin{tabular}{|c|c|c|c|c|c|c|c|}
\hline $\begin{array}{l}\text { Thickiness } \\
\lambda\end{array}$ & $\begin{array}{l}\text { Edep } \\
\text { MeV }\end{array}$ & & $\begin{array}{l}\text { Eclep } \\
\% \\
\text { loMreV }\end{array}$ & $\begin{array}{l}\text { Edep } \\
\% \\
5 \mathrm{MleV}\end{array}$ & $\begin{array}{l}\text { Edep } \\
\% \\
\text { INeV }\end{array}$ & $\begin{array}{l}\text { Eelep) } \\
\% \\
\text { 300ker }\end{array}$ & $\begin{array}{l}\text { Expl. } \\
\% \\
\left(1+\int ?\right)\end{array}$ \\
\hline 1 & $17: 3.6$ & FMC & $37.2 \pm .5$ & $3: 3.1 \pm .5$ & $33.8 \pm .5$ & $36.1 \pm .5$ & $30.7 \pm .1$ \\
\hline $\begin{array}{l}2 \\
3 \\
4\end{array}$ & $\begin{array}{l}150.5 \\
85.20 \\
37.30\end{array}$ & IIAC!! & & & & $.56 .7 \pm .5$ & $50.3 \pm .1$ \\
\hline $\begin{array}{l}5 \\
6 \\
7\end{array}$ & $\begin{array}{l}20.10 \\
9.90 \\
4.80\end{array}$ & IIAC:11 & & & & $7.2 \pm .5$ & $(i .9 \pm .1$ \\
\hline
\end{tabular}

TA13LE 11

Salicnt Features of the Three Configurations

\begin{tabular}{|c|c|c|c|}
\hline & 1) $U-S(' I N$ & $P \mid)-S(! I N$ & In-SC'IN \\
\hline Absorber medium & Depl.tranium & Lead & lion \\
\hline Nedive modium & Scintillator & Sciutillator & Scinlillalor \\
\hline Alssorber Thickness & $0.33 \mathrm{~cm}$ & $1.00 \mathrm{~cm}$ & $2.5 \mathrm{~cm}$ \\
\hline Scintillator Thickness & $0.26 \mathrm{~cm}$ & $0.25 \mathrm{~cm}$ & $1.00 \mathrm{~cm}$ \\
\hline Radiation Length & $0.50 \mathrm{~cm}$ & $0.70 \mathrm{~cm}$ & $2.12 \mathrm{~cm}$ \\
\hline Nuclear Int. length & $17.0 \mathrm{~cm}$ & $20.3 \mathrm{~cm}$ & 22.115 ( \\
\hline Arerage Densit! & $11.0 .5 \mathrm{gm} / \mathrm{cm}^{3}$ & $9.20 \mathrm{gm} / \mathrm{rm}^{3}$ & $5.7 !) \mathrm{g} m / 1 \mathrm{~cm} \mathrm{~m}^{3}$ \\
\hline (ilobal Dimensions & $60^{46} 60 \mathrm{~cm}^{2}$ & (i0)"60 $\mathrm{cm}^{2}$ & $(\mathrm{il})^{-\mathrm{r}}\left(\mathrm{i}() \mathrm{cmll}^{2}\right.$ \\
\hline
\end{tabular}


TABLE III

e/h Ratio

\begin{tabular}{|c|c|c|}
\hline & Simu. & Expt. \\
\hline DUISCSN & $1.03 \pm 0.07$ & $1.01 \pm 0.0 .1 \quad(1 \in f \mathfrak{g})$ \\
\hline$P ا-S C S N$ & $1.05 \pm 0.0 \tau$ & $1.0 .5 \pm 0.02(i \in f O)$ \\
\hline Pe-SC'SN & $1.36 \pm 0.10$ & $1.40 \pm 0.10($ off 1.4$)$ \\
\hline
\end{tabular}

TABLE IV

Comparison of Resolutions

\begin{tabular}{|c|c|c|c|c|}
\hline & Electrons & $\left(\operatorname{lr} \int 1: 3\right)$ & Pions & $(\operatorname{ref} 1.3)$ \\
\hline $\begin{array}{l}\text { Energy } \\
\text { (Ciri) }\end{array}$ & $\underset{1 / 4}{S i m u .}$ & $\begin{array}{l}\text { Expt. } \\
\qquad \%\end{array}$ & $\begin{array}{l}\text { Simu. } \\
\%\end{array}$ & $\begin{array}{r}\text { Expl. } \\
\%\end{array}$ \\
\hline 5.0 & $J(i .9)$ & $17.9 \pm 0.2$ & $39 . \overline{1}$ & $3 \cdot 1.5 \pm 0.5$ \\
\hline 10.0 & 16.8 & $10.5 \pm 0.5$ & 37.8 & $33.2 \pm 0.5$ \\
\hline
\end{tabular}

\begin{tabular}{|c|c|c|c|c|}
\hline \multirow{2}{*}{ PB-SCII } & & & & \\
\hline & Filarelens & $\left(\operatorname{lrc} \int 9\right)$ & Pions & $(\operatorname{lr}(9)$ \\
\hline Energy & Simu. & Expl. & Simu. & Expt. \\
\hline (Ciel) & $\%$ & $\%$ & $\%$ & $\%$ \\
\hline 10.0 & $2+.9$ & $22.6 \pm 0.2$ & 6S.S & $44.2 \pm 1.3$ \\
\hline
\end{tabular}

\begin{tabular}{|c|c|c|c|c|}
\hline \multicolumn{5}{|c|}{ PIE-SC'IN } \\
\hline & Electrons & $(\operatorname{lef})$ & Pions & $(\operatorname{lof} 1\})$ \\
\hline Energ! & Simu. & Expl. & Simun. & Expt. \\
\hline (Gel) & & $1 \%$ & 7 & $y$ \\
\hline 10.0 & & & (iii..3 & (i!).j)士:3.0) \\
\hline 25.0 & & & $(i 1.5)$ & $T(1.0 \pm 3.0$ \\
\hline
\end{tabular}


ZEUS Prototype Modules $4 P-1$
(DU/Scint SCSN $38+$ WLS Y 7 )

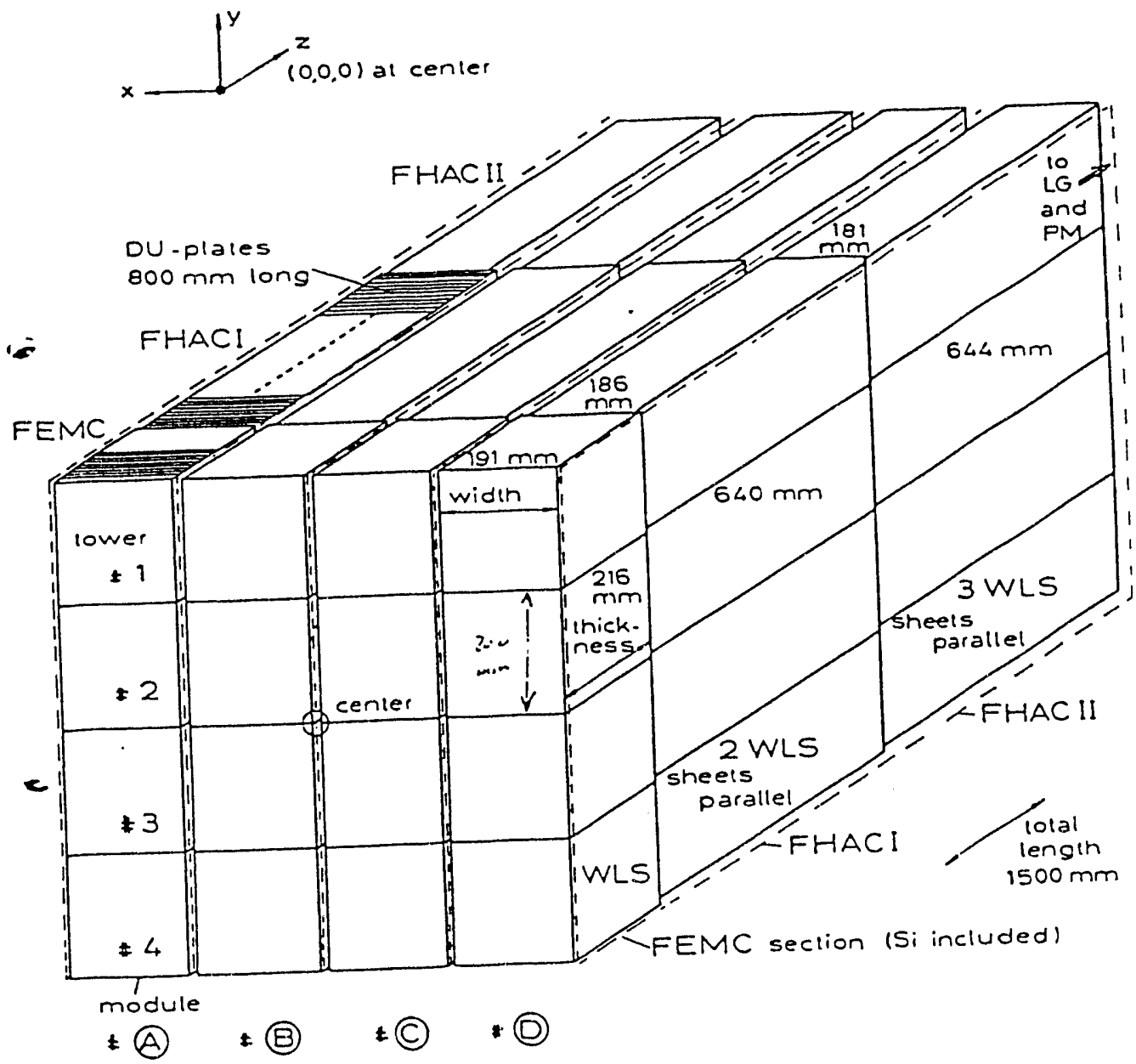

FIC . .1 


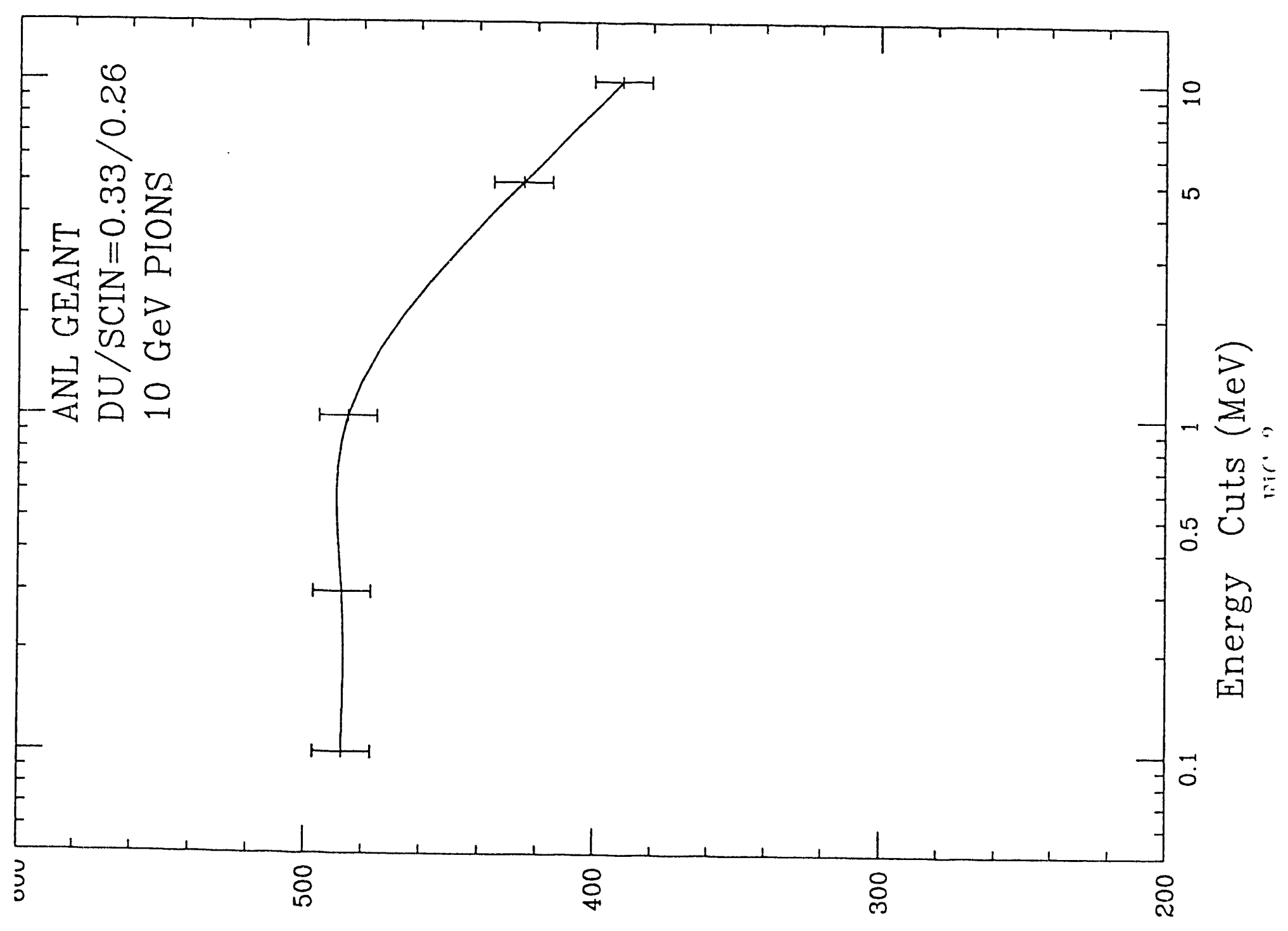

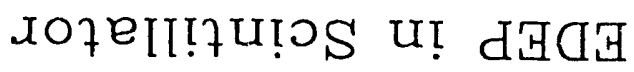


EDEP in Scintillator

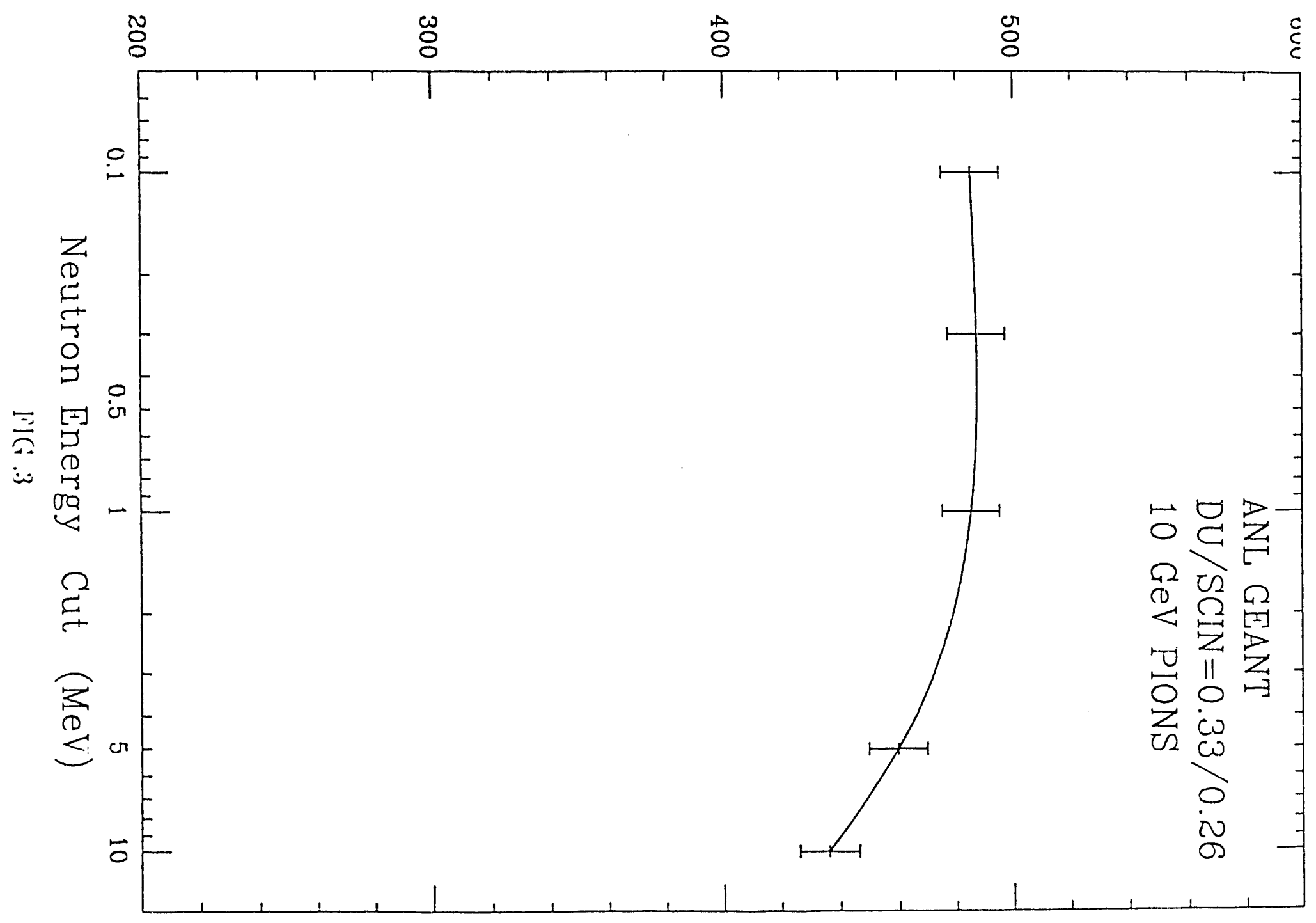




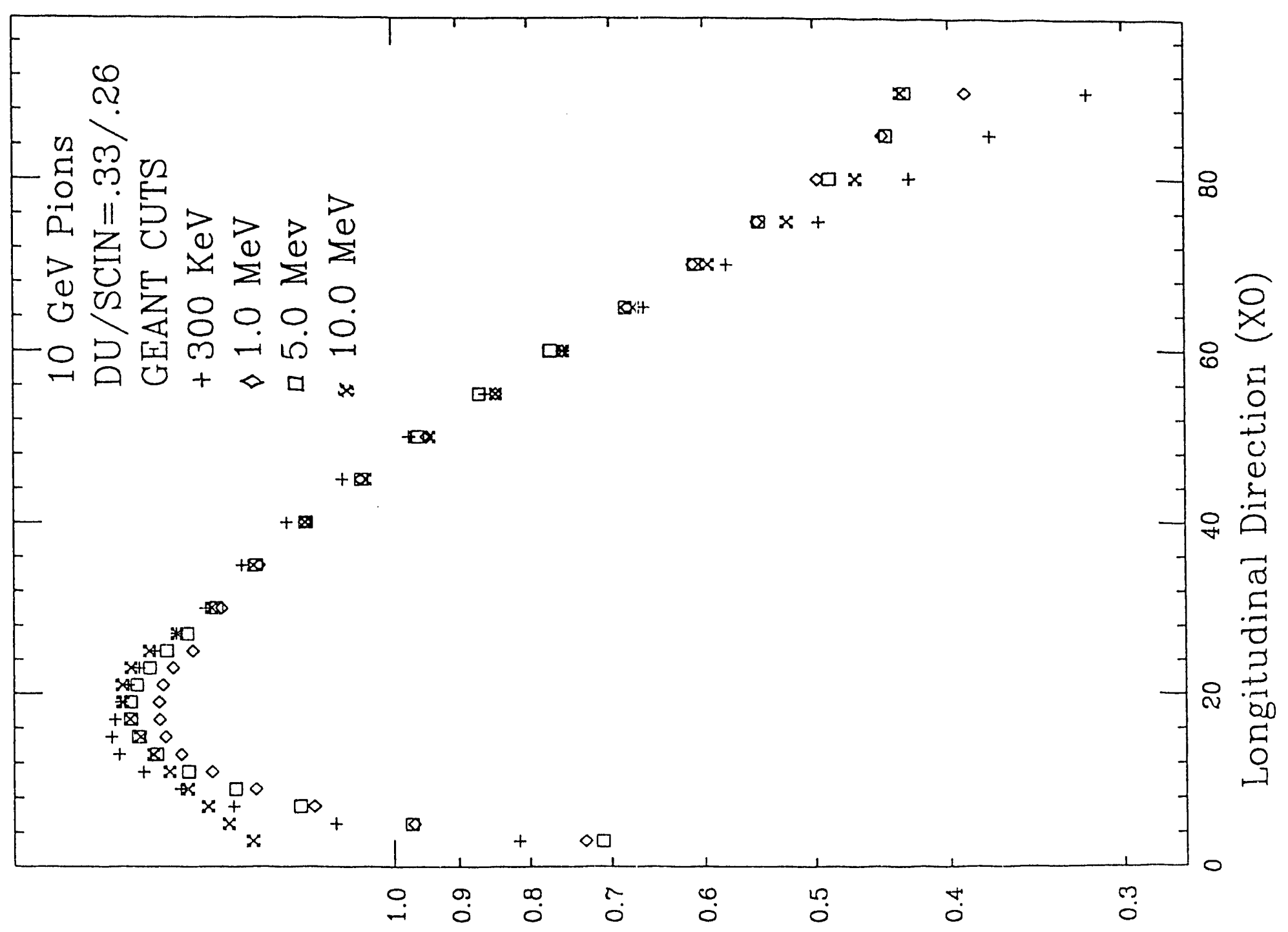

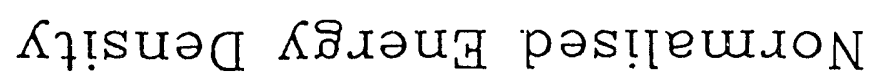




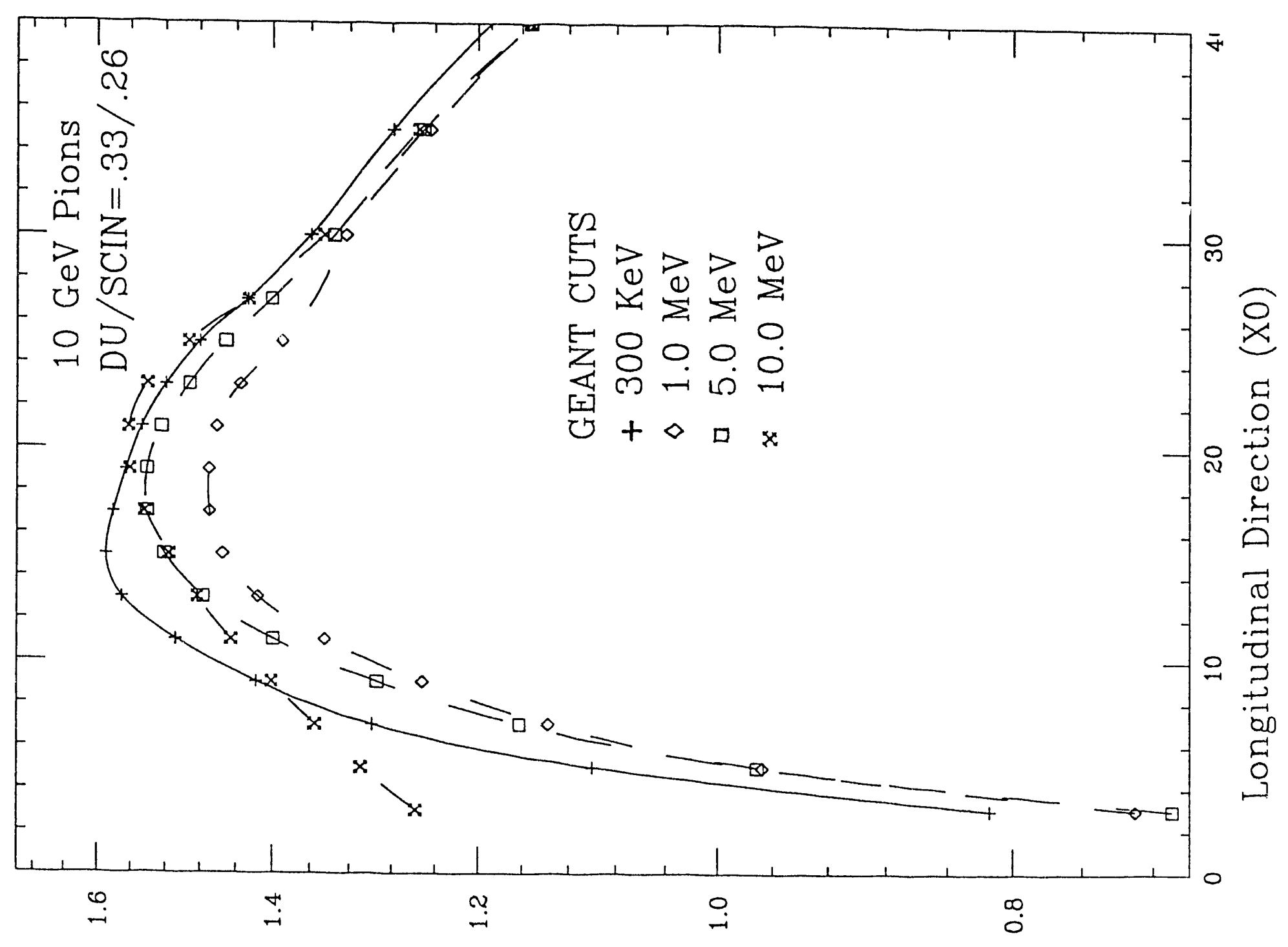

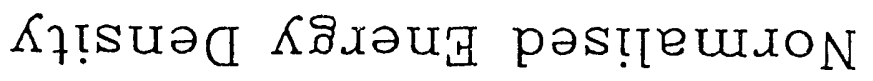




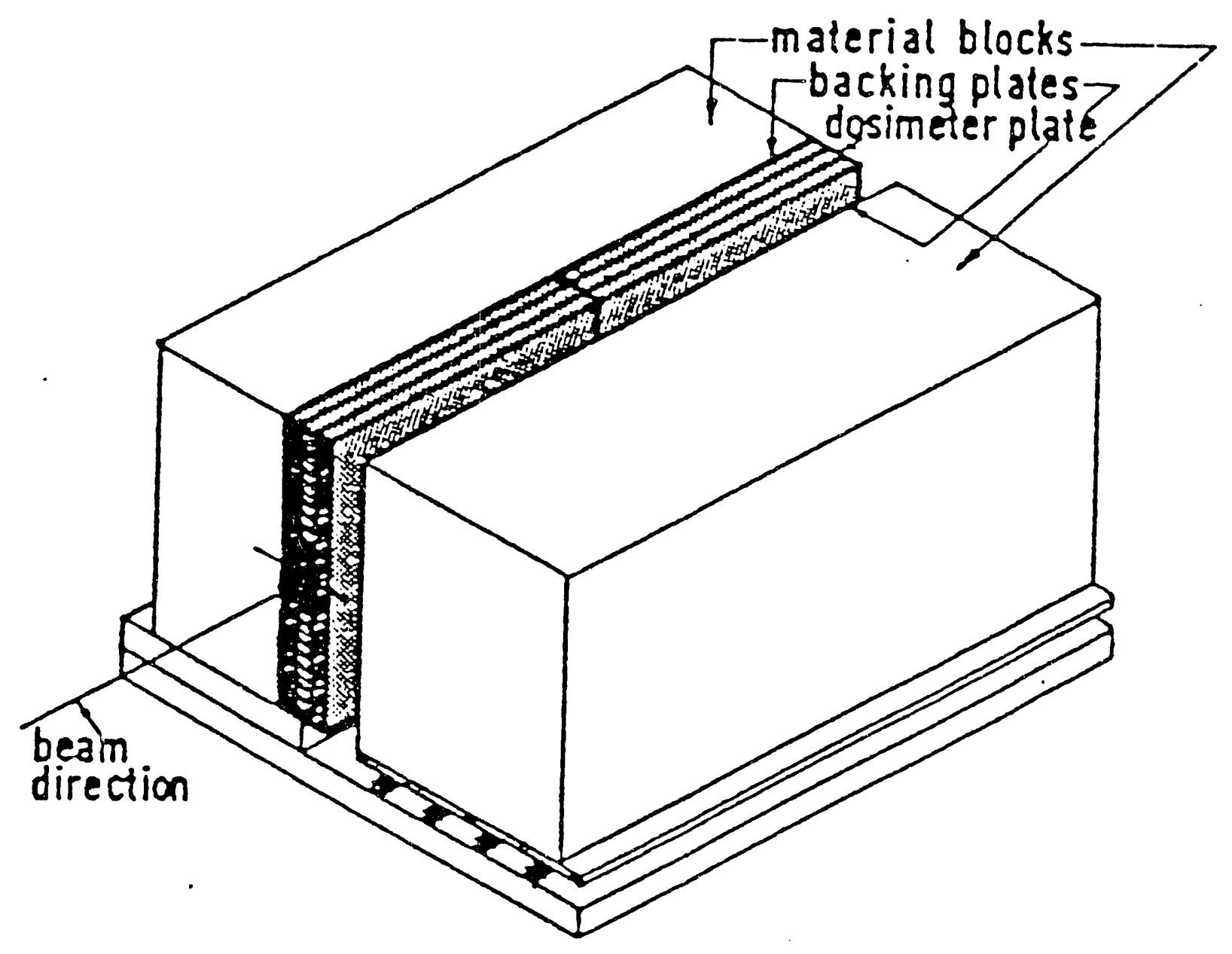

FIC . .5 


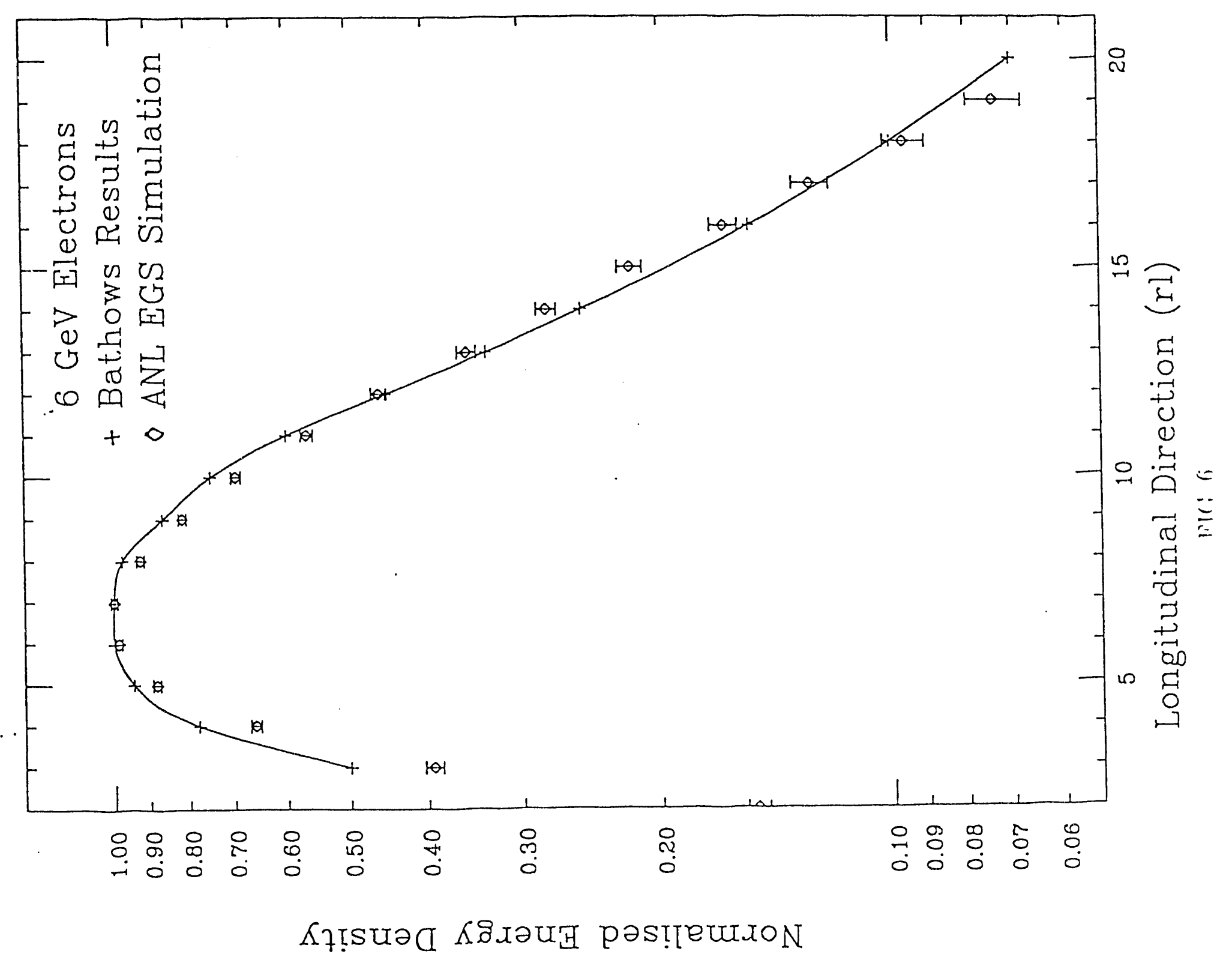




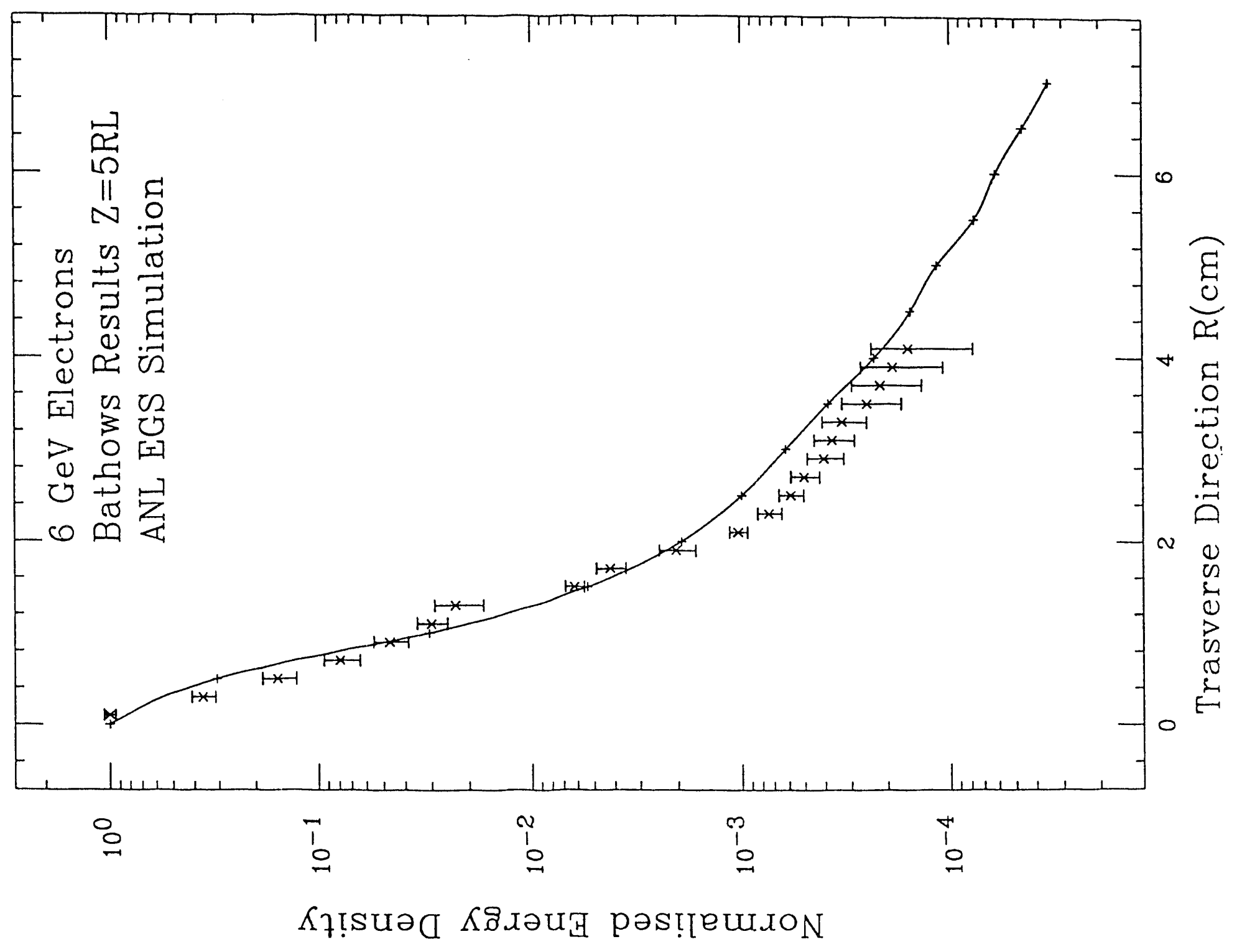




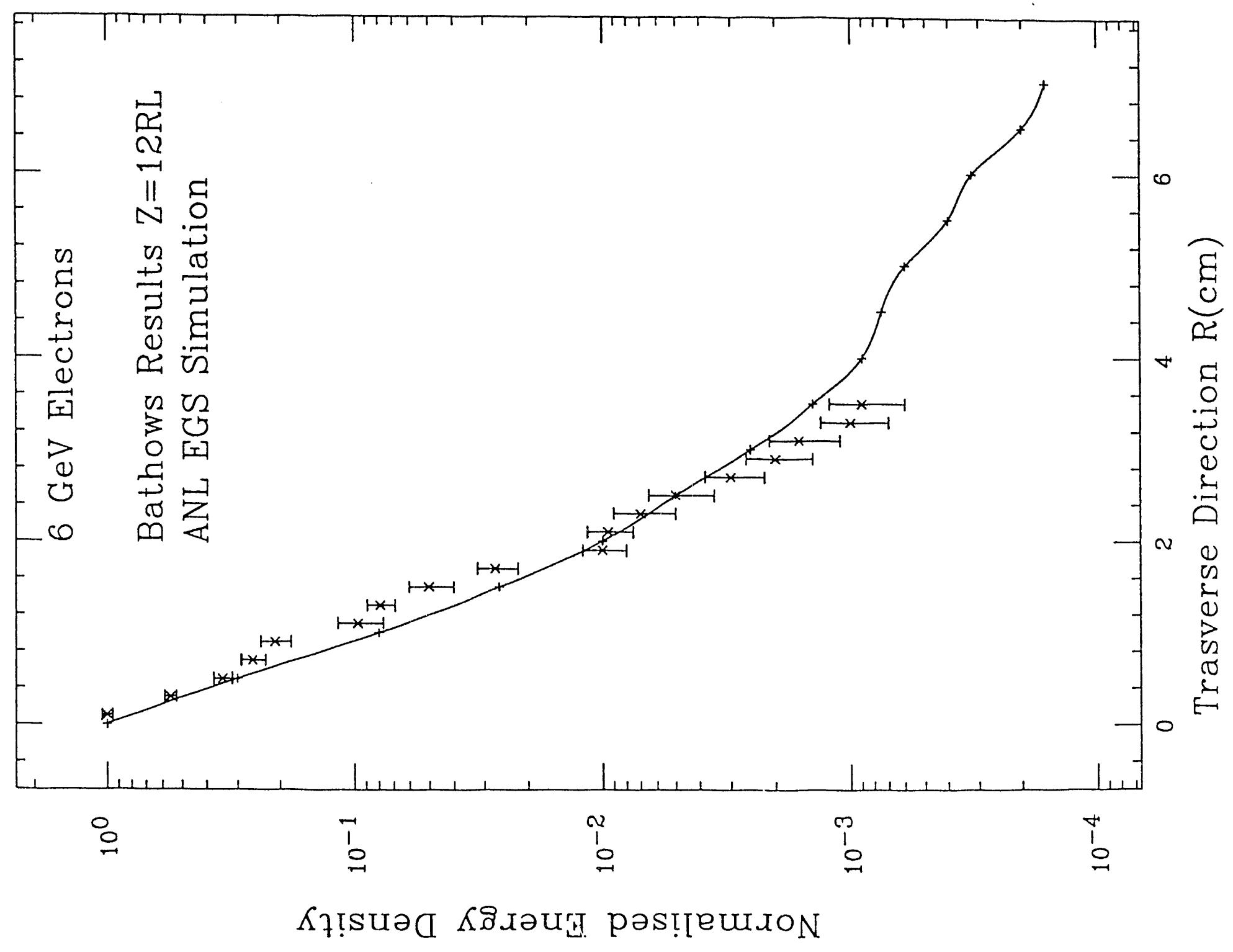




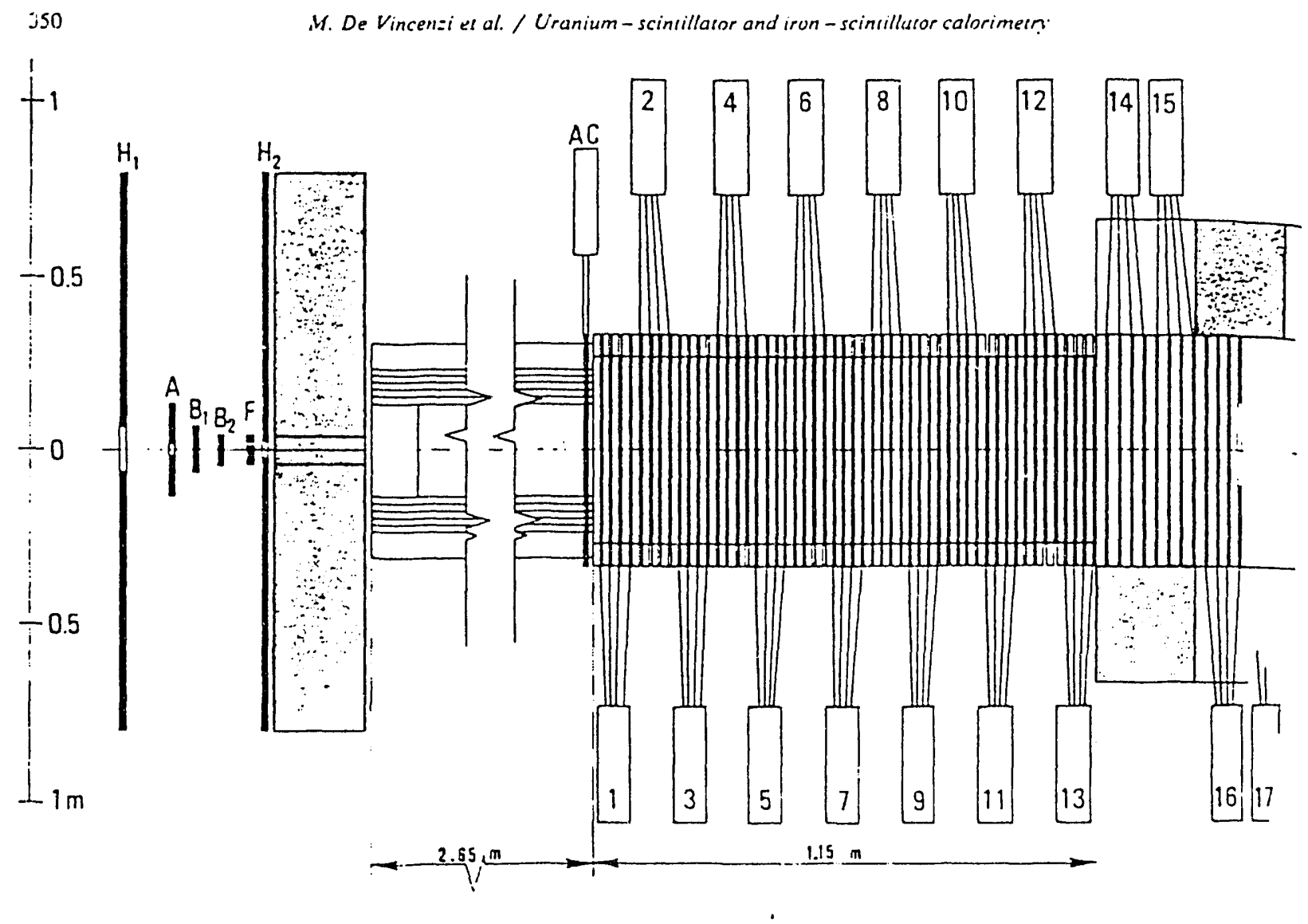

FIC: .9 


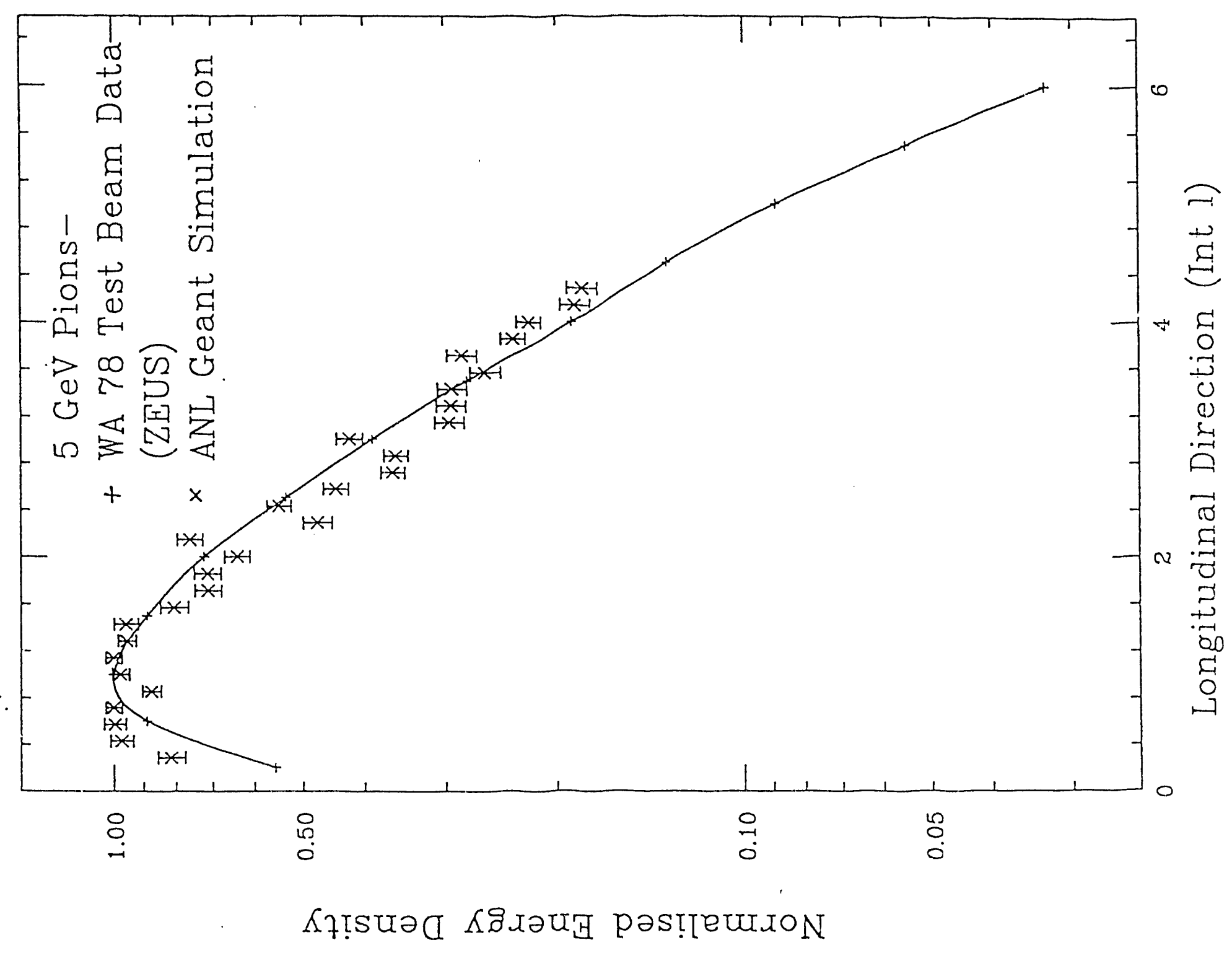




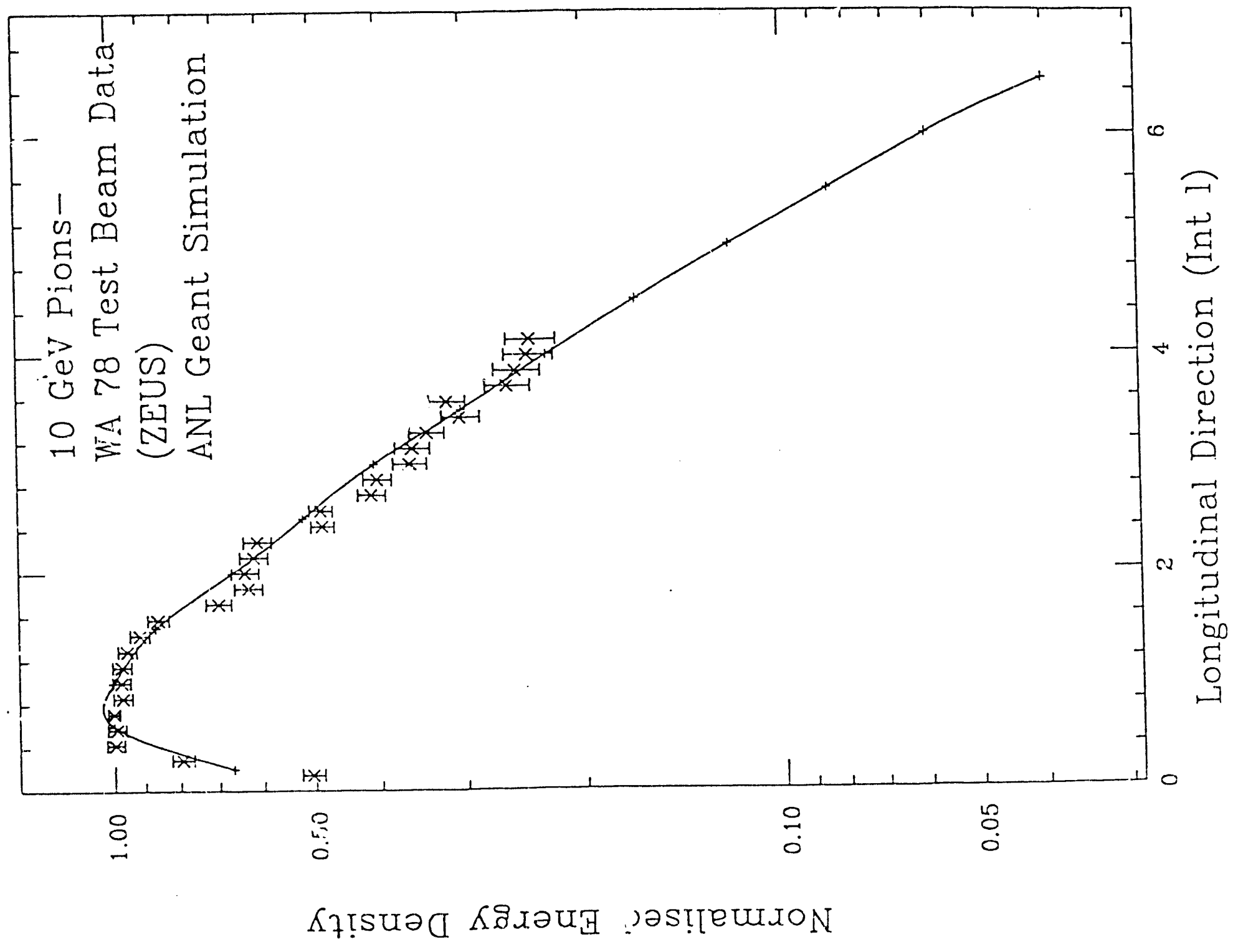




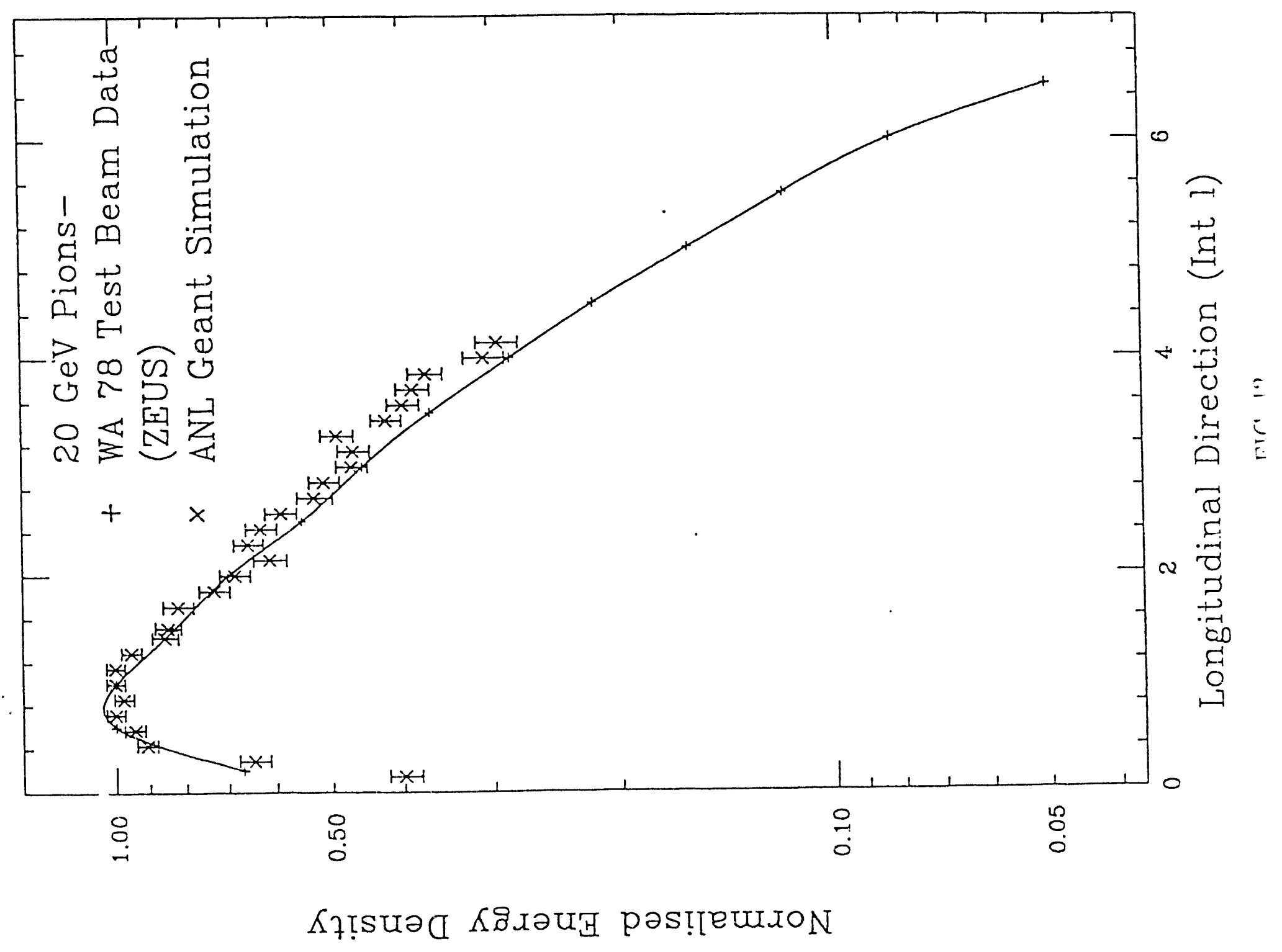




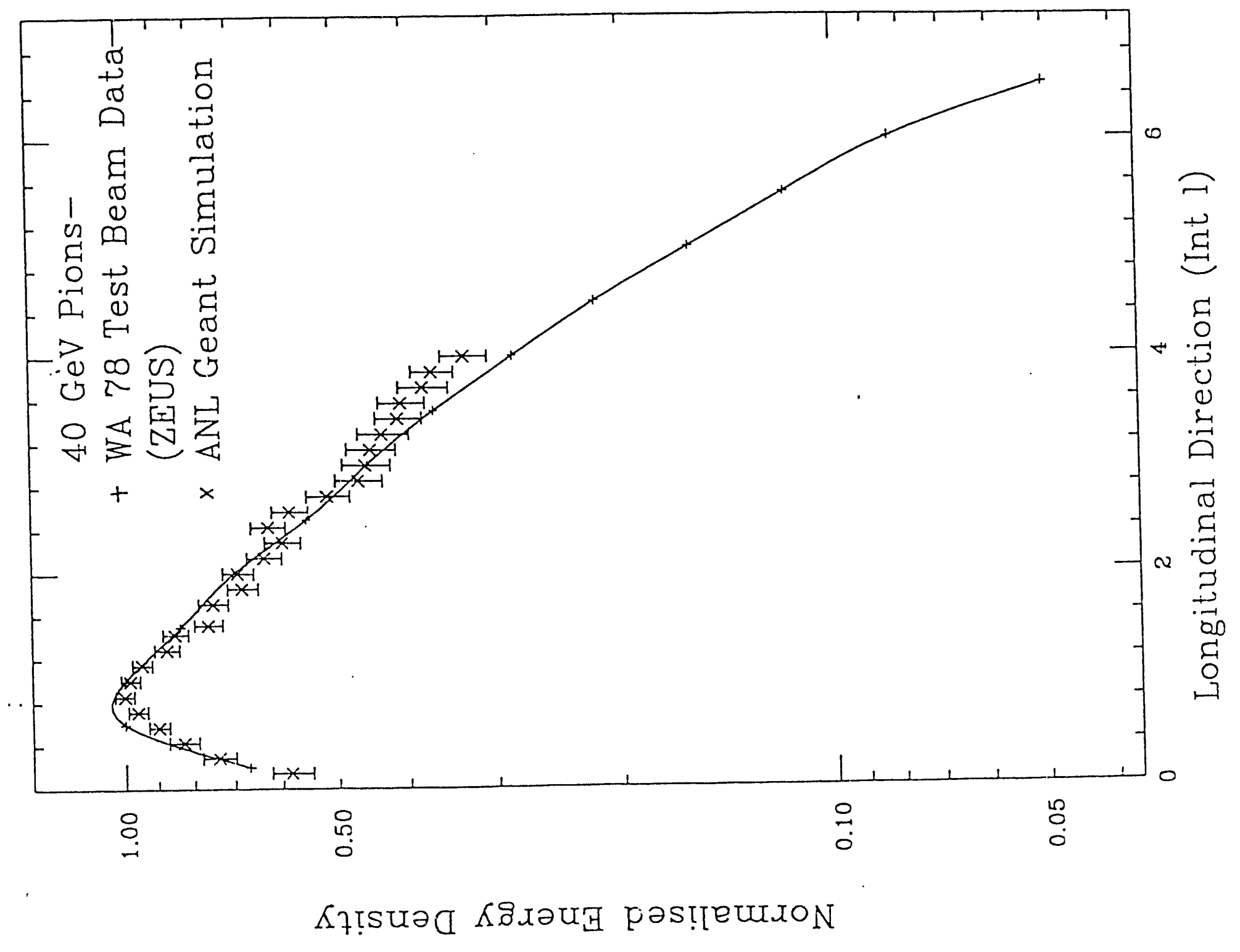




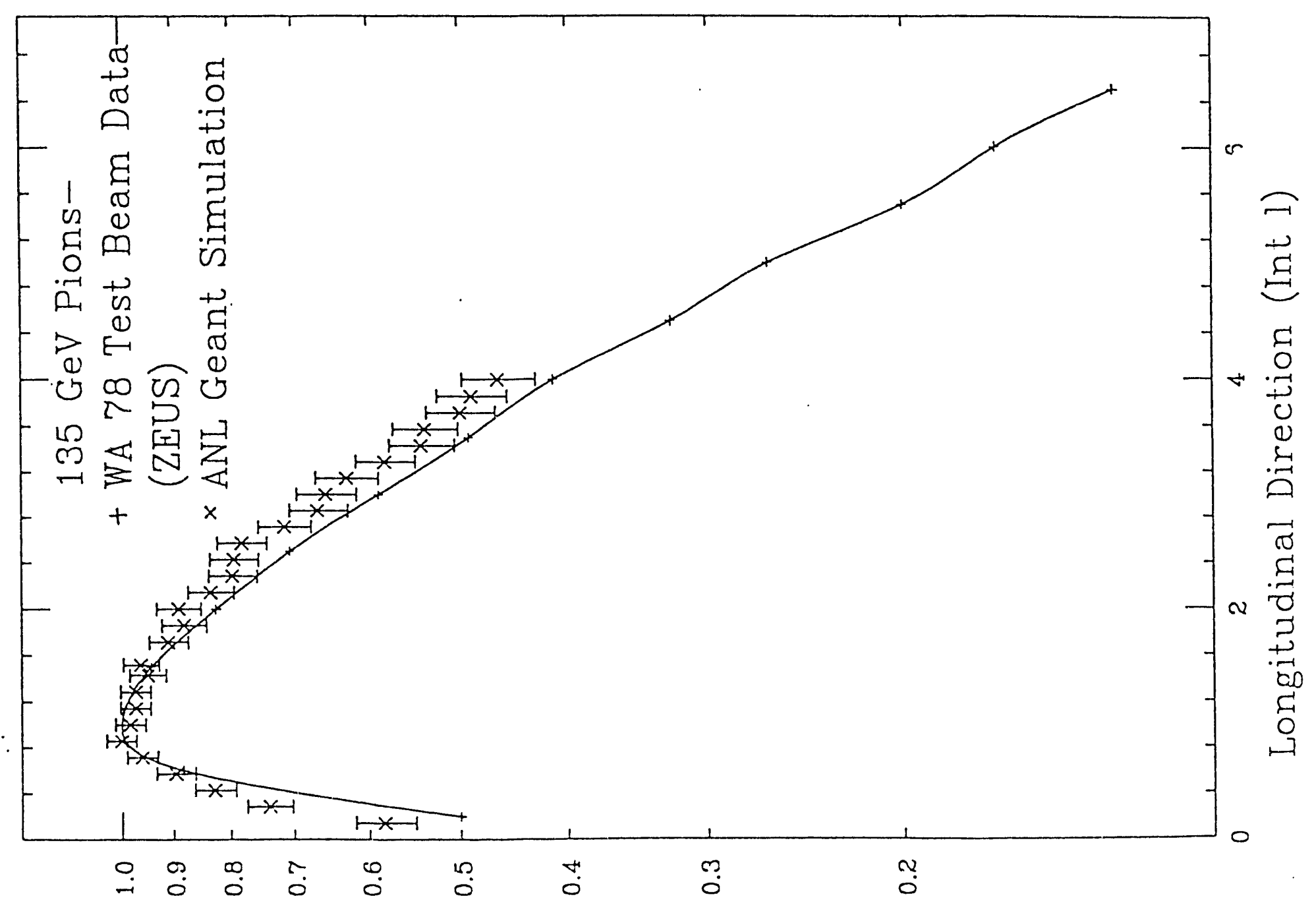

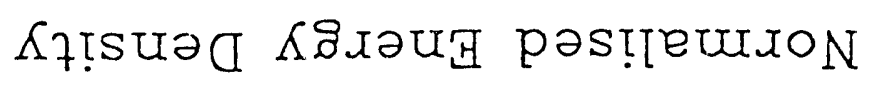




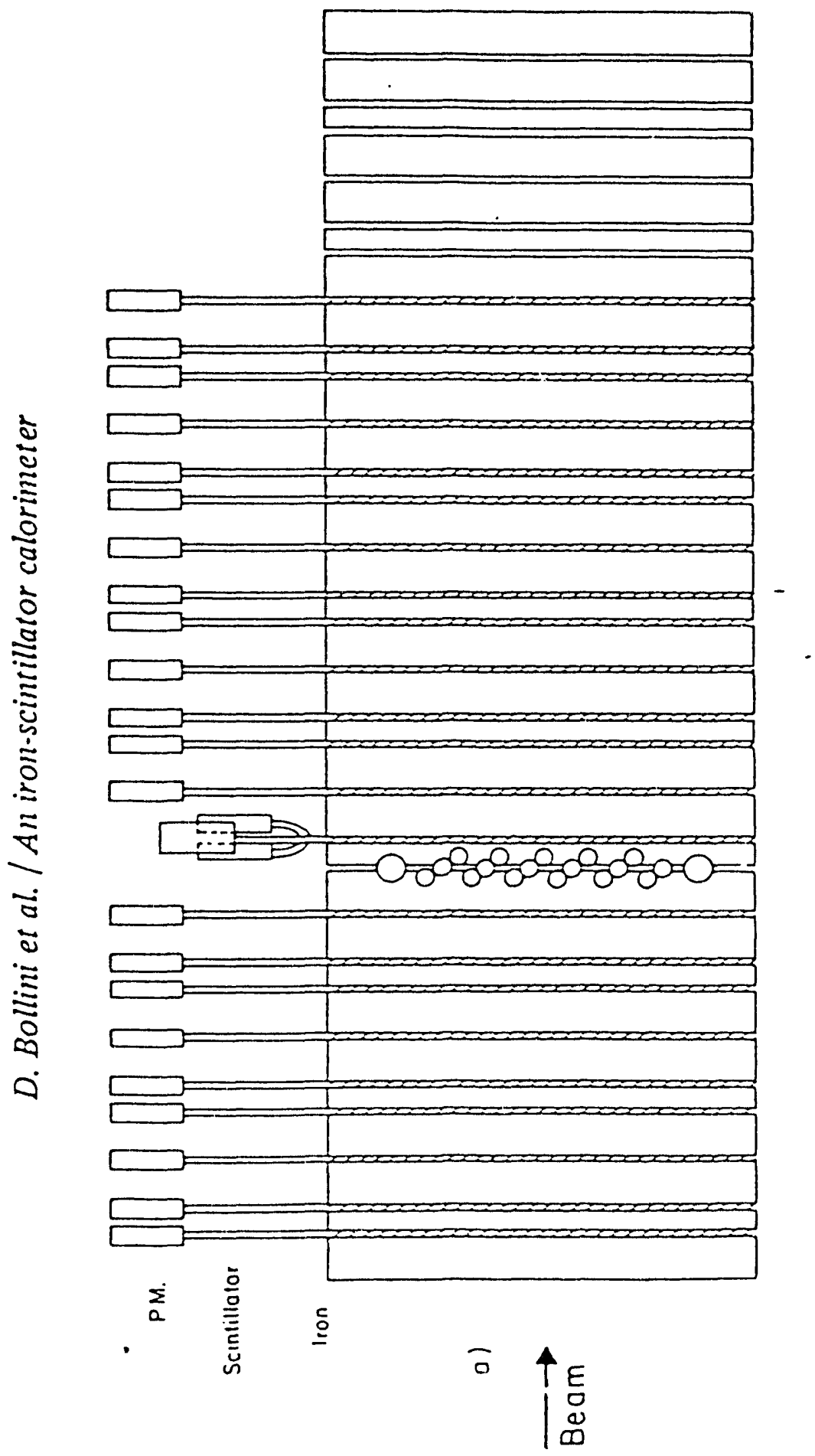




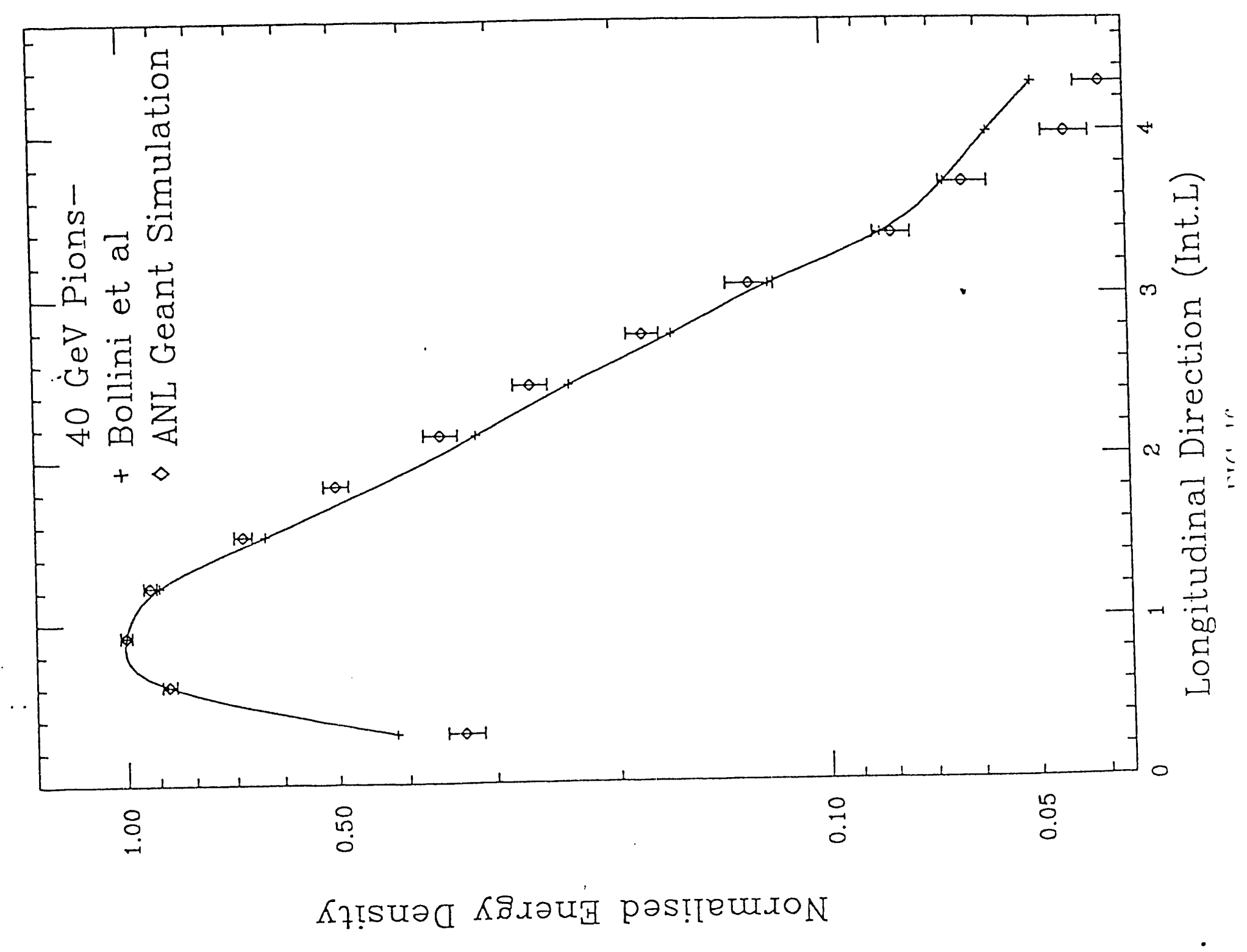




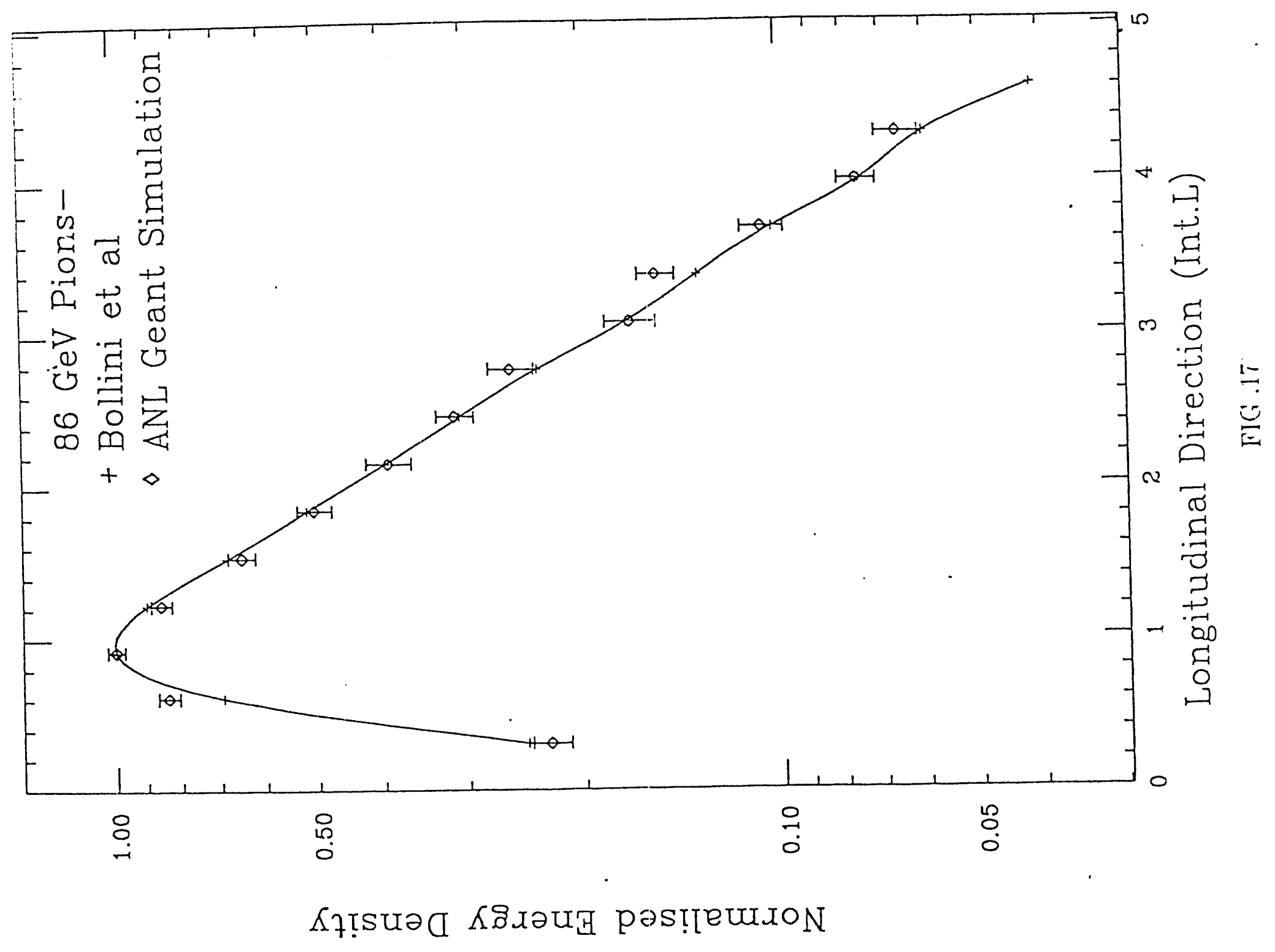




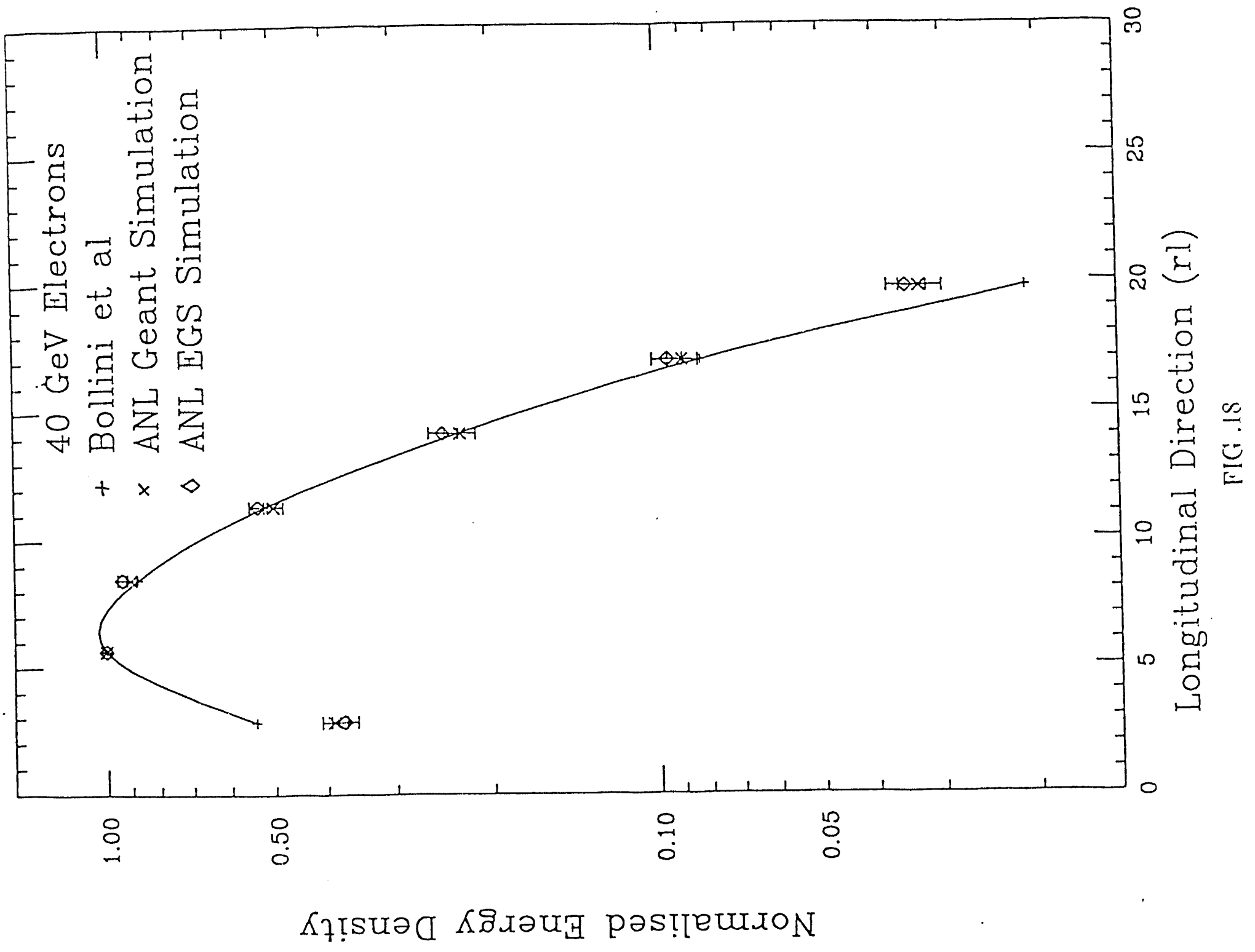




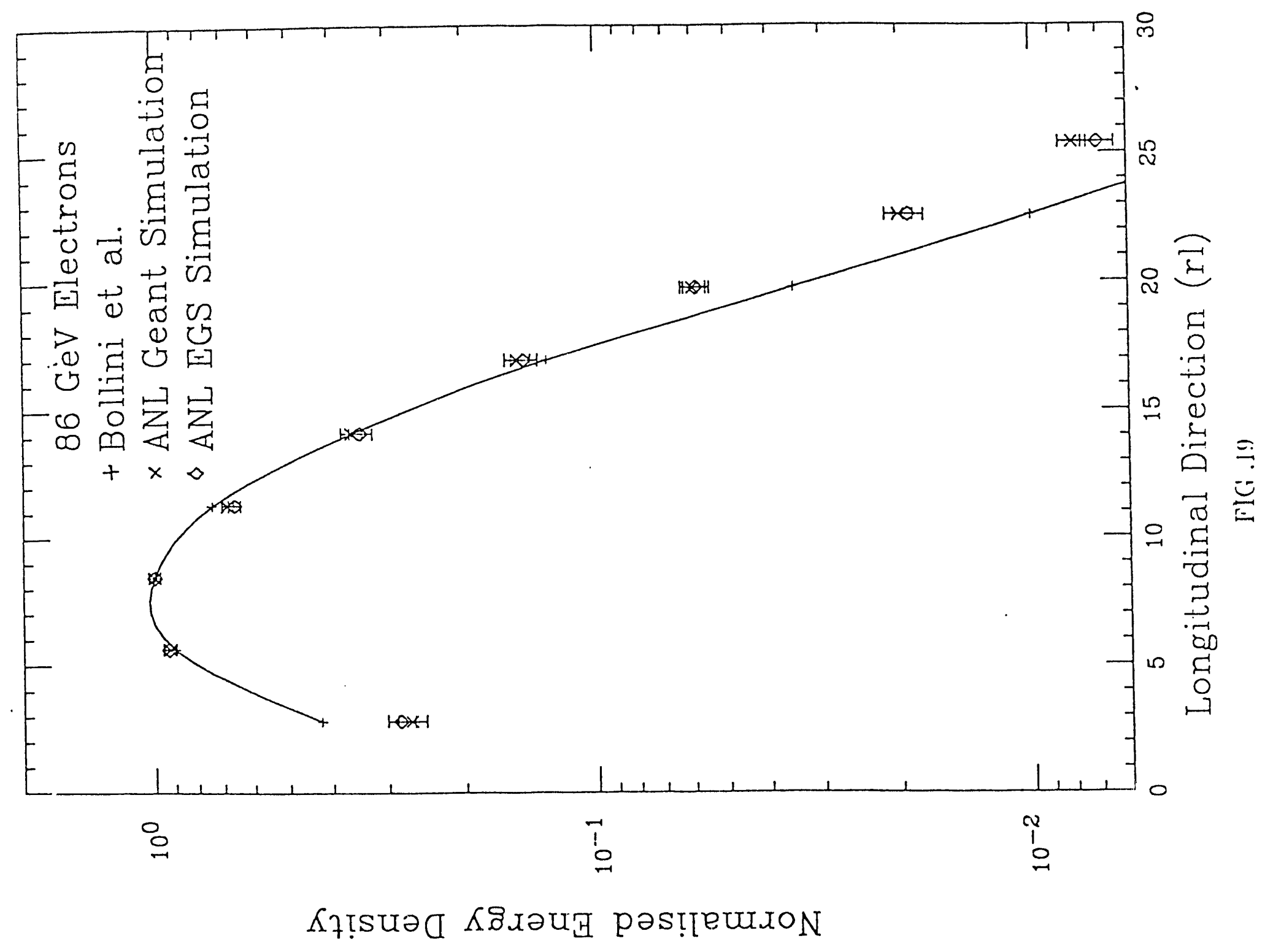




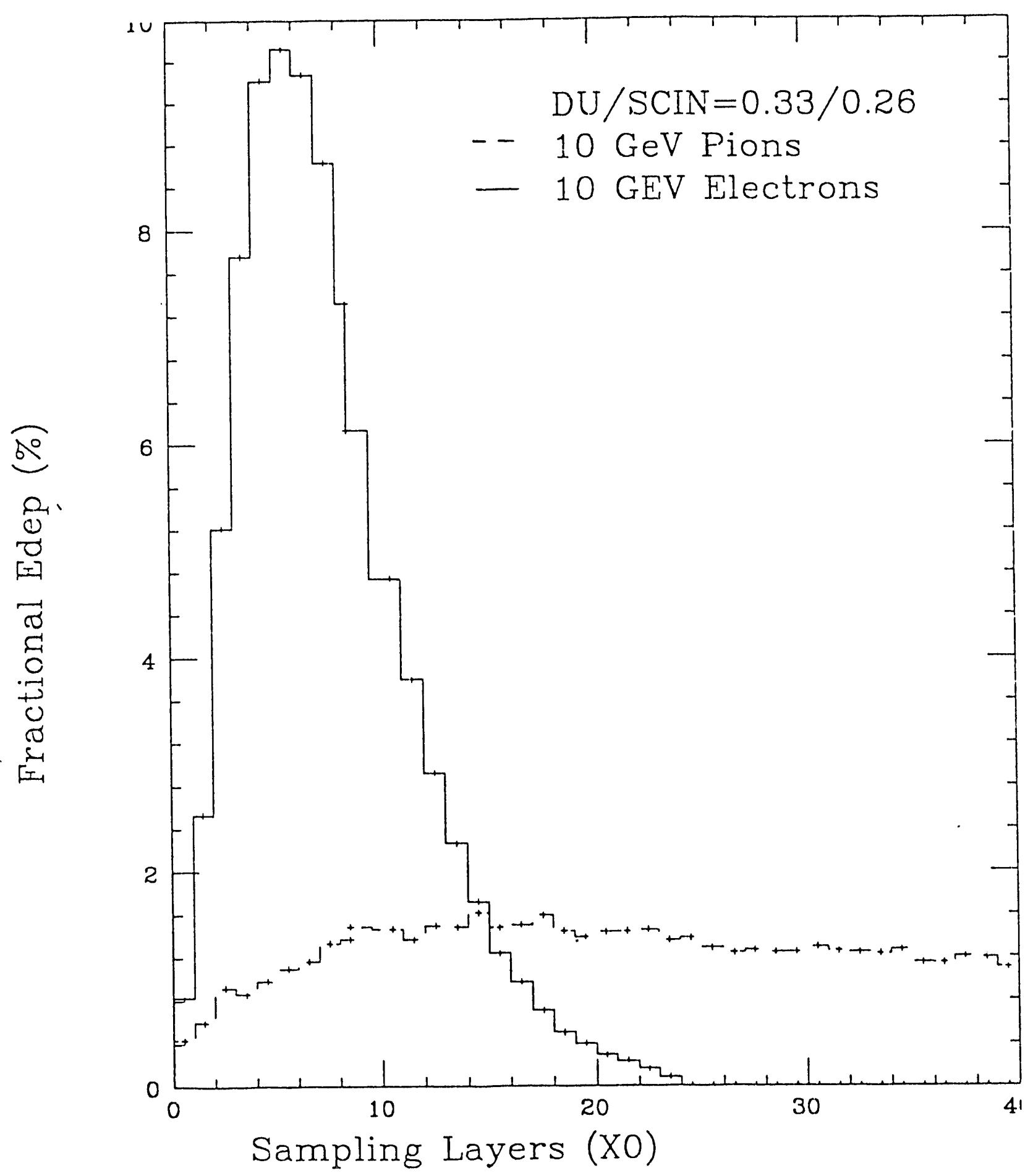

JFIG 20 


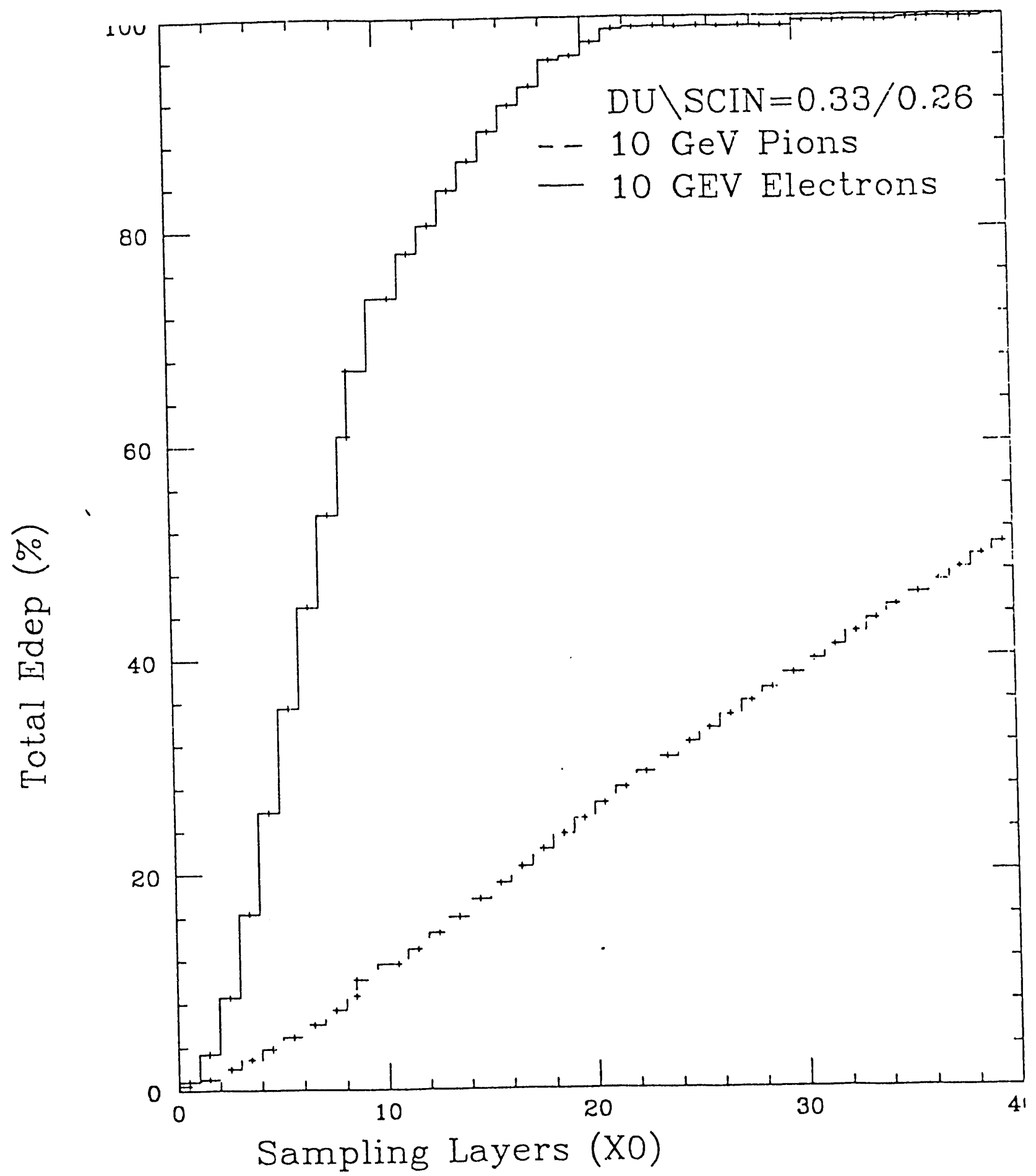

FIC .2] 


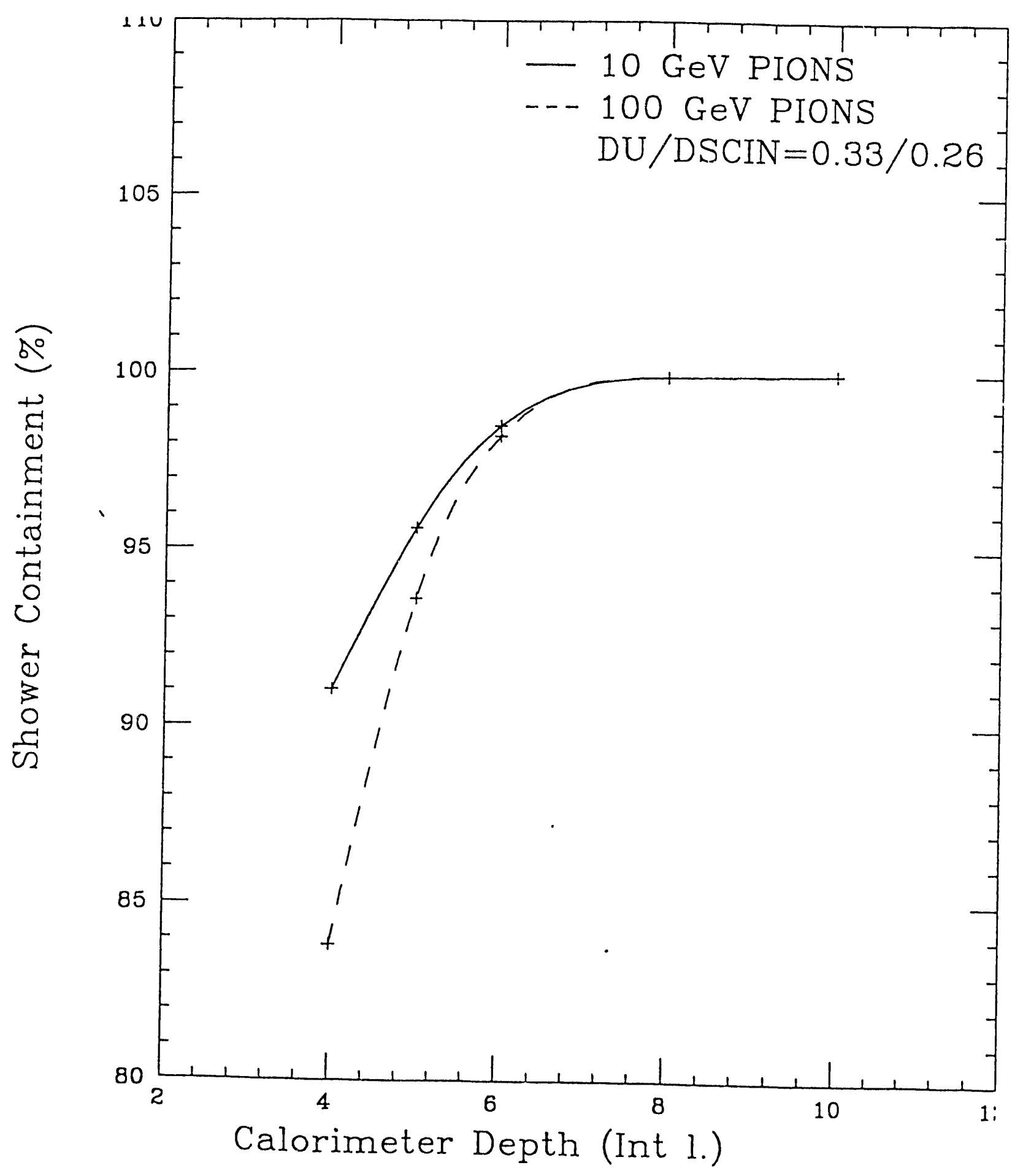

FIC .22 


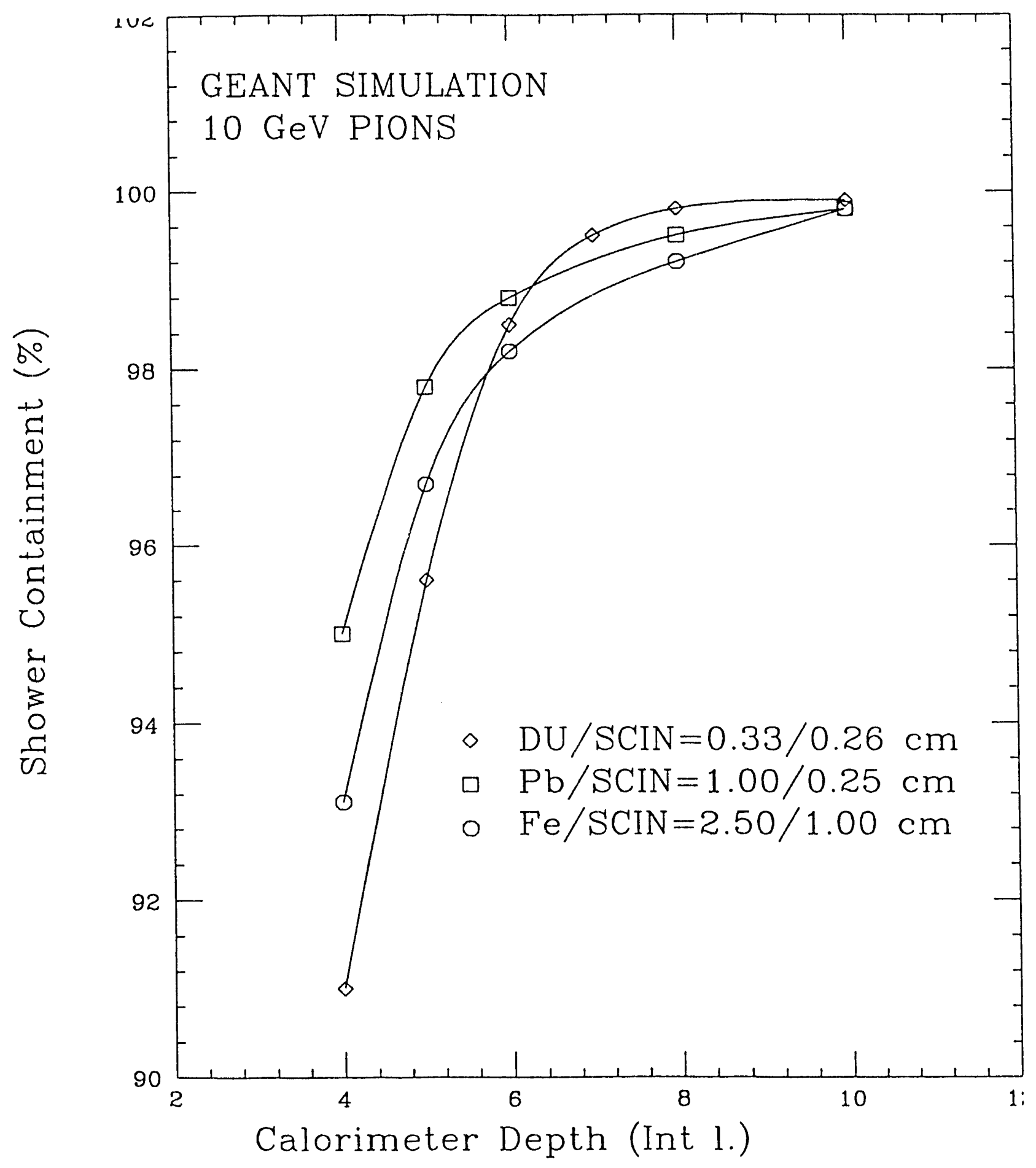

FIG .23 


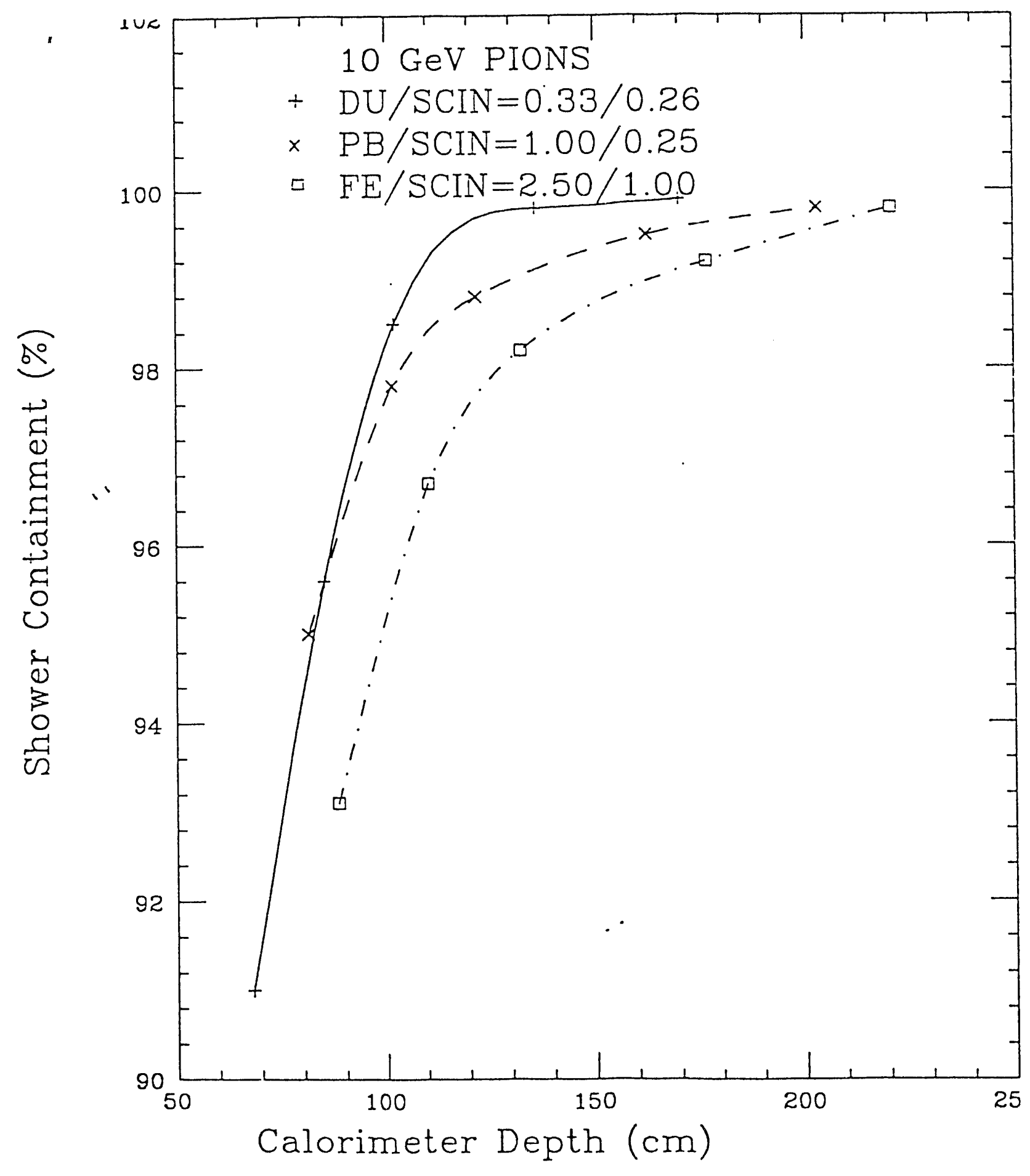

FIG .2. A 


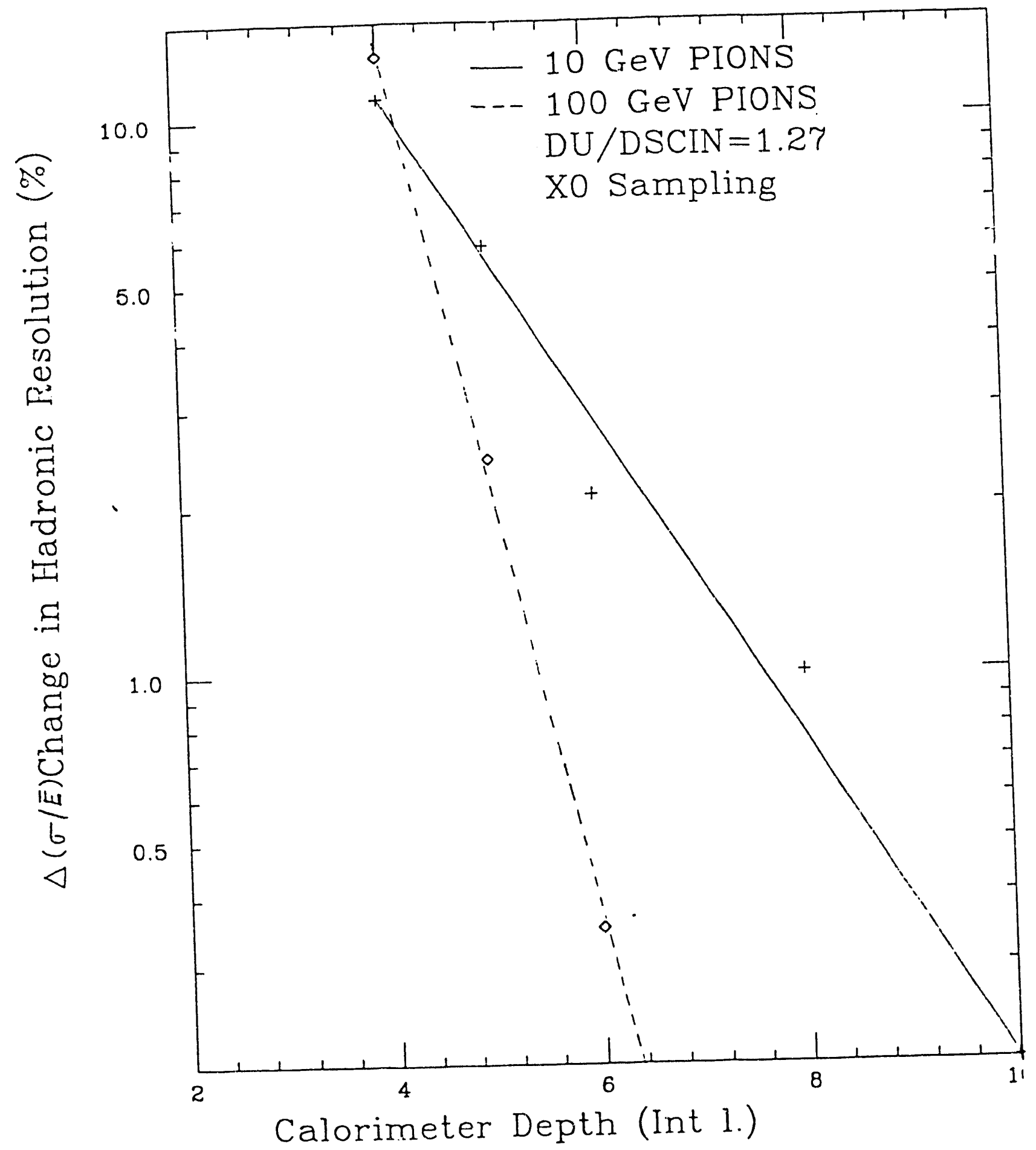

FIC: 2. 


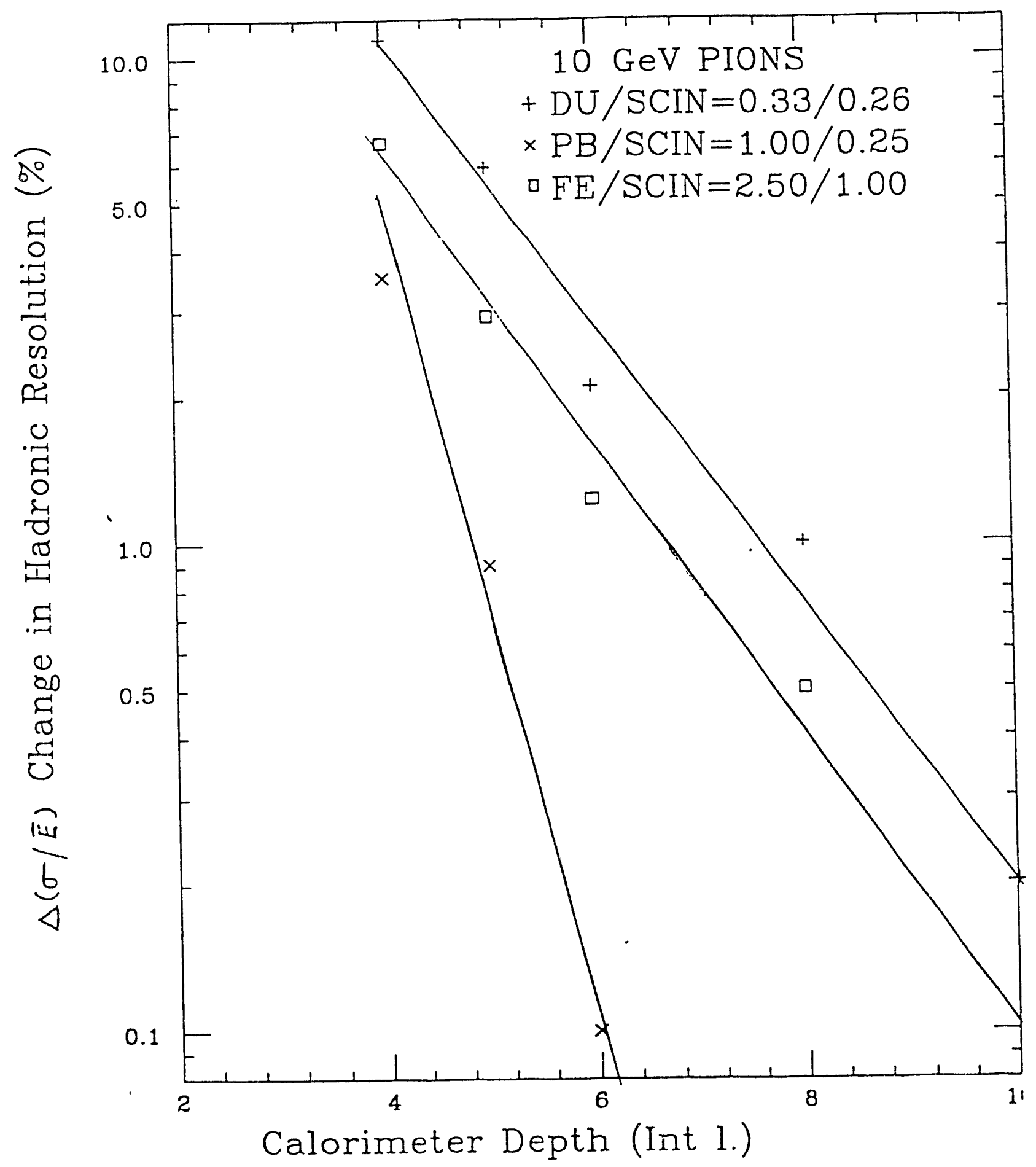

FiC .25 


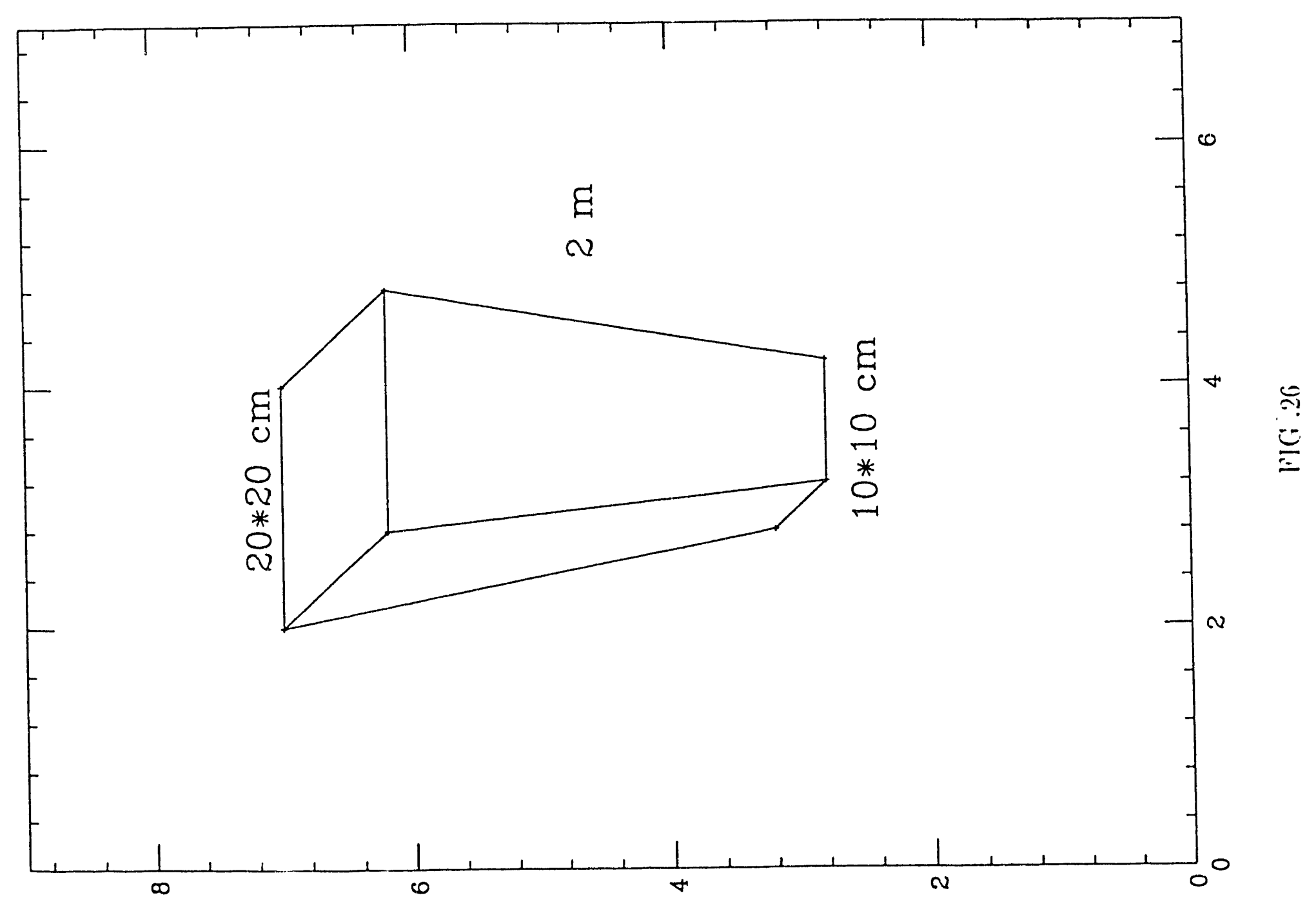




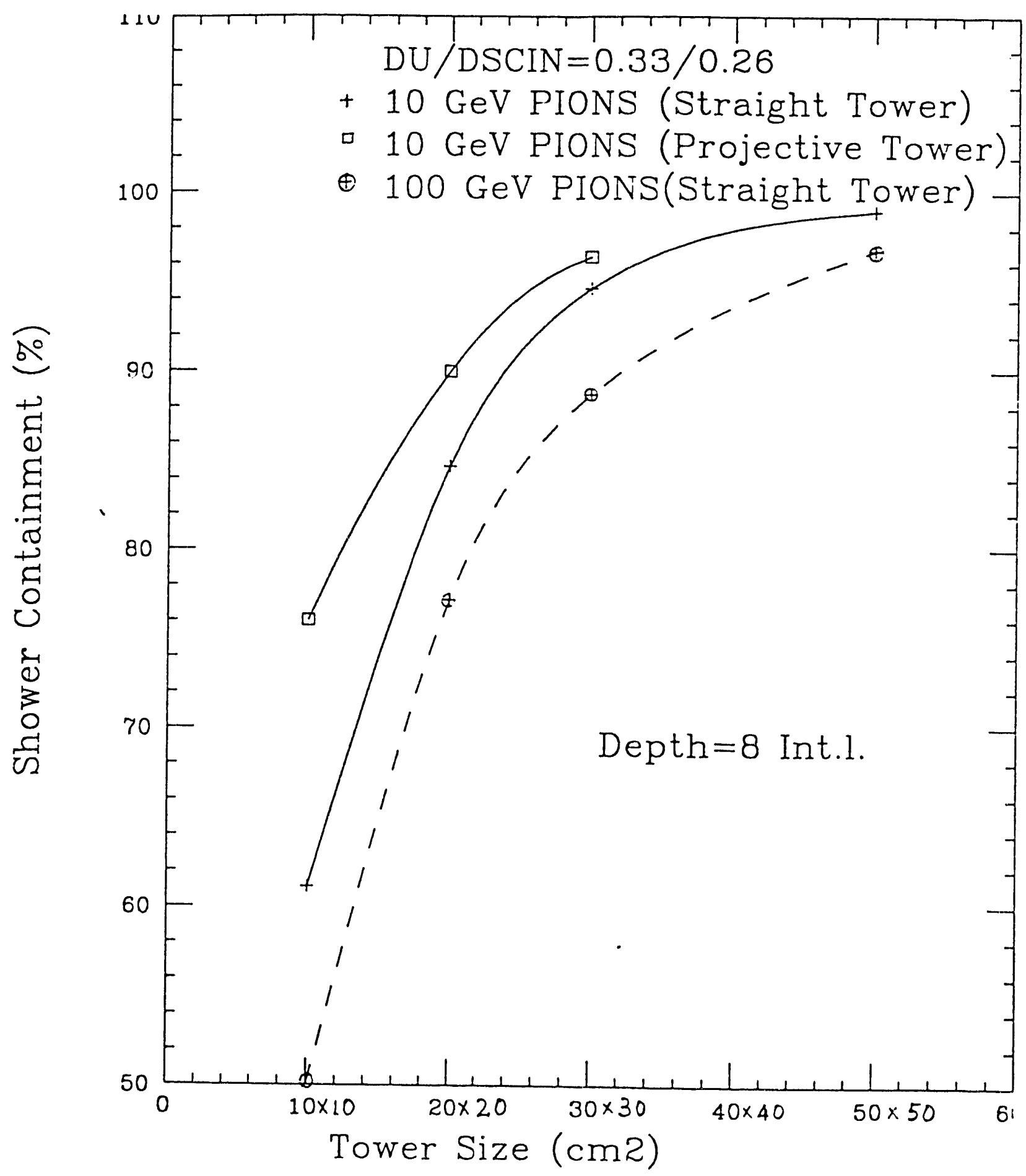

HKi $2 T$ 


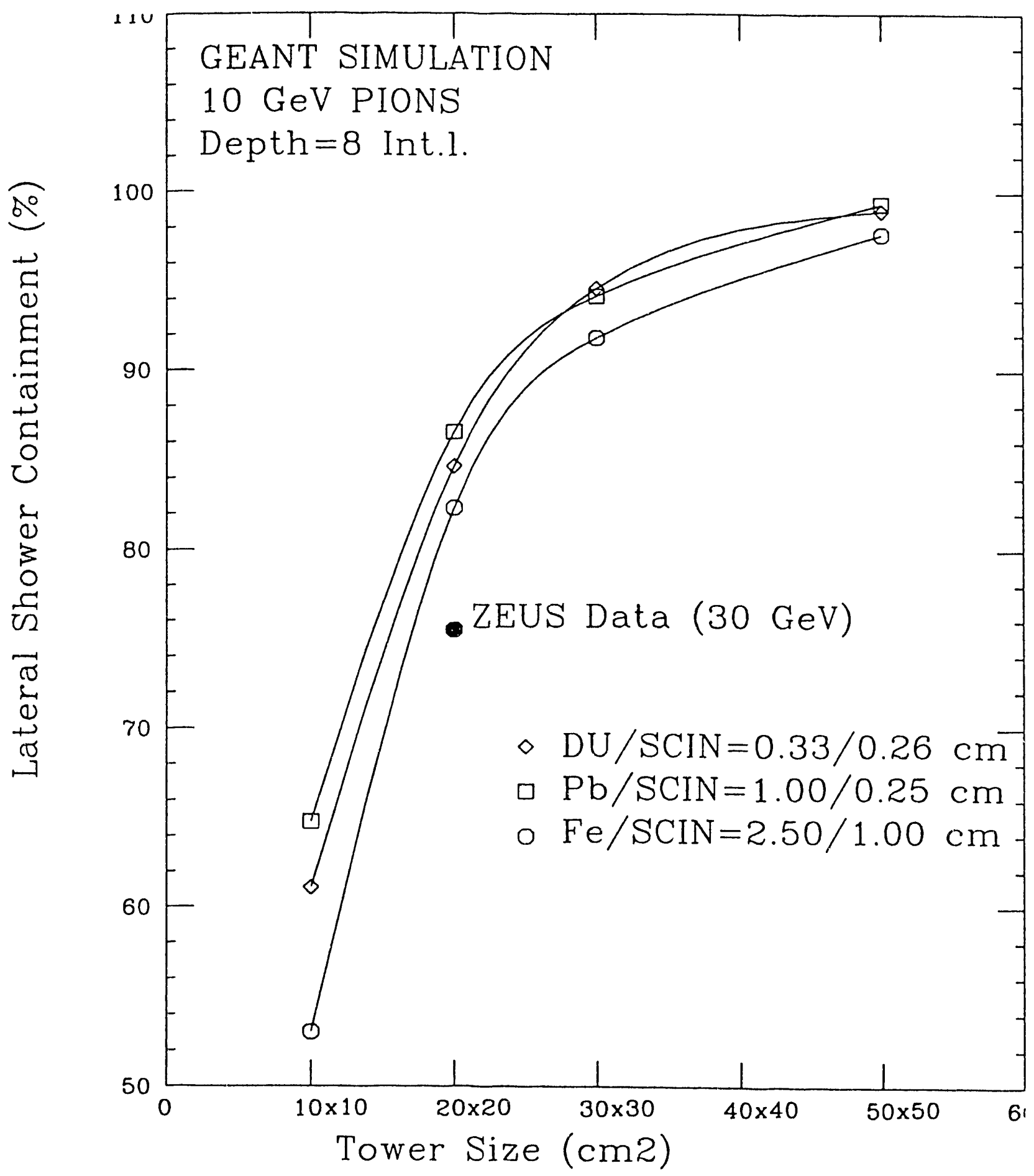

FIC .28 


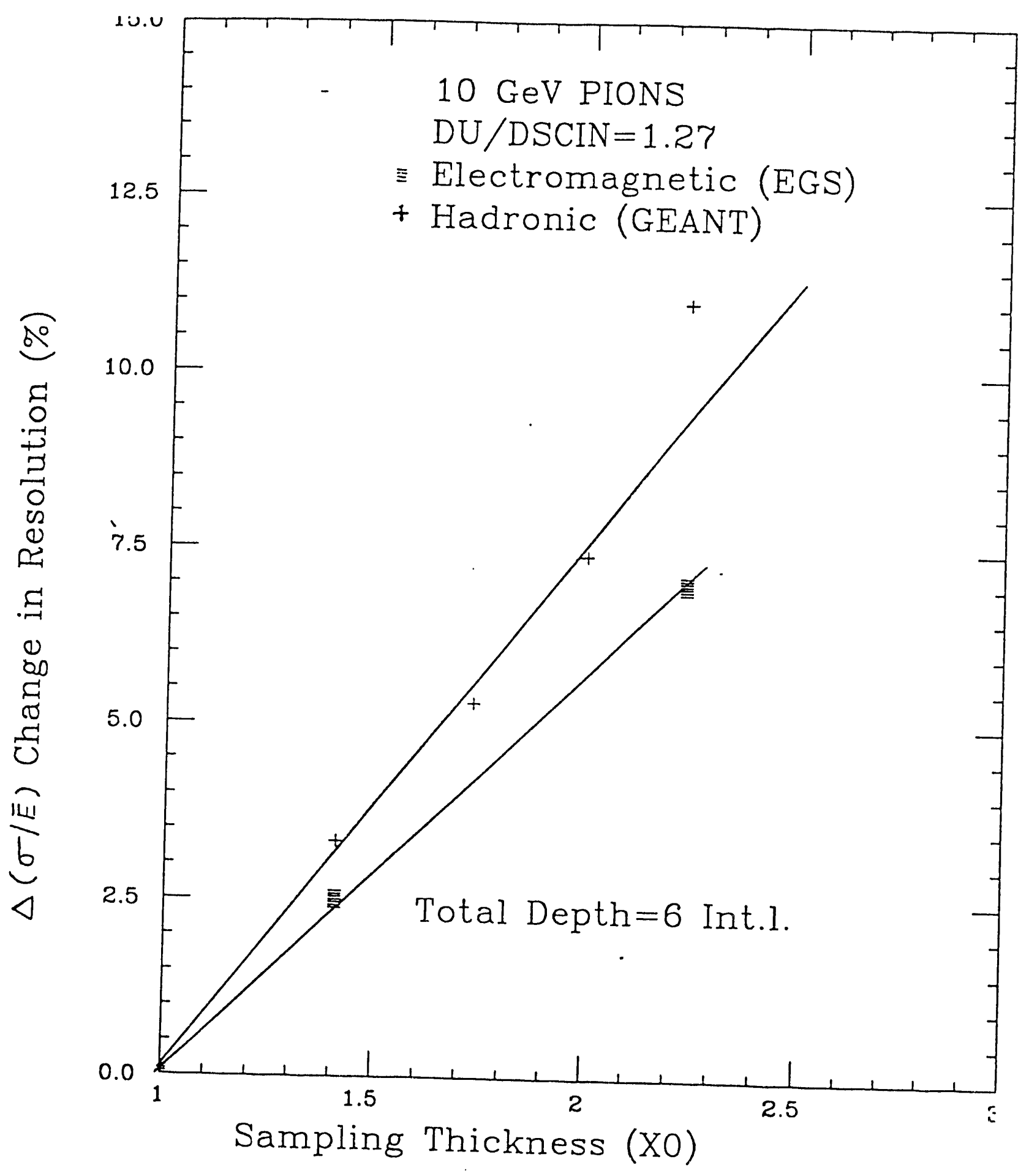

FIC 29 


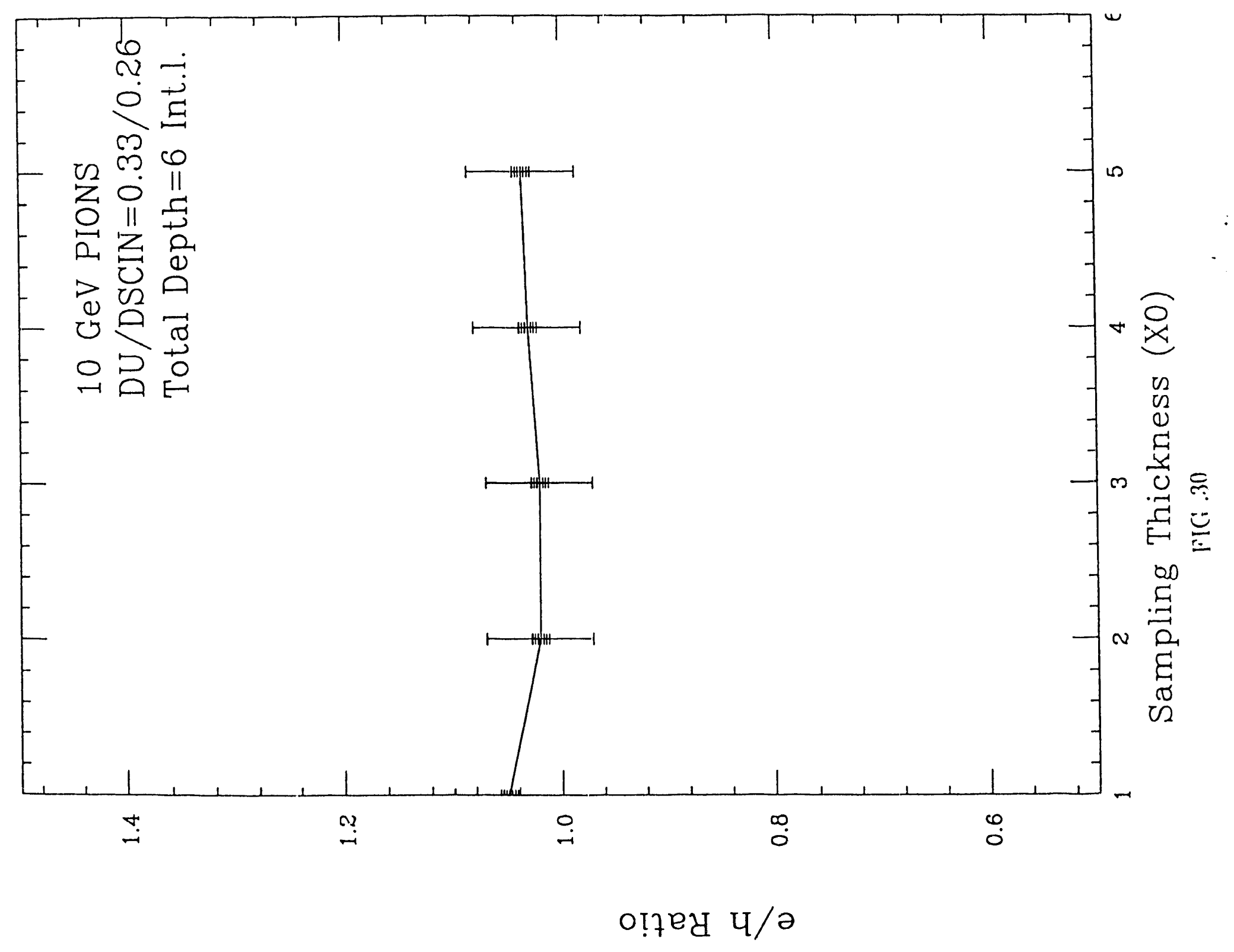




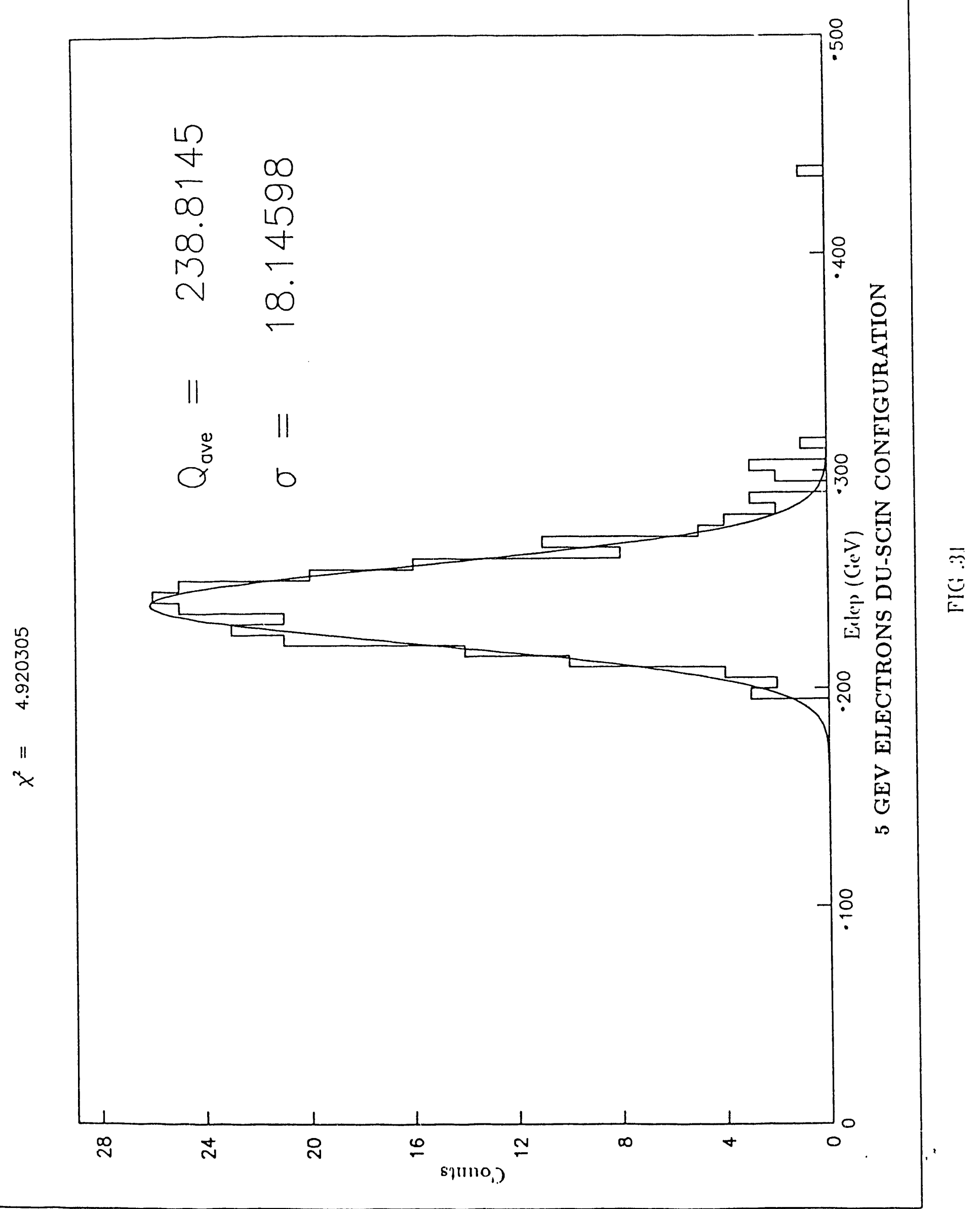




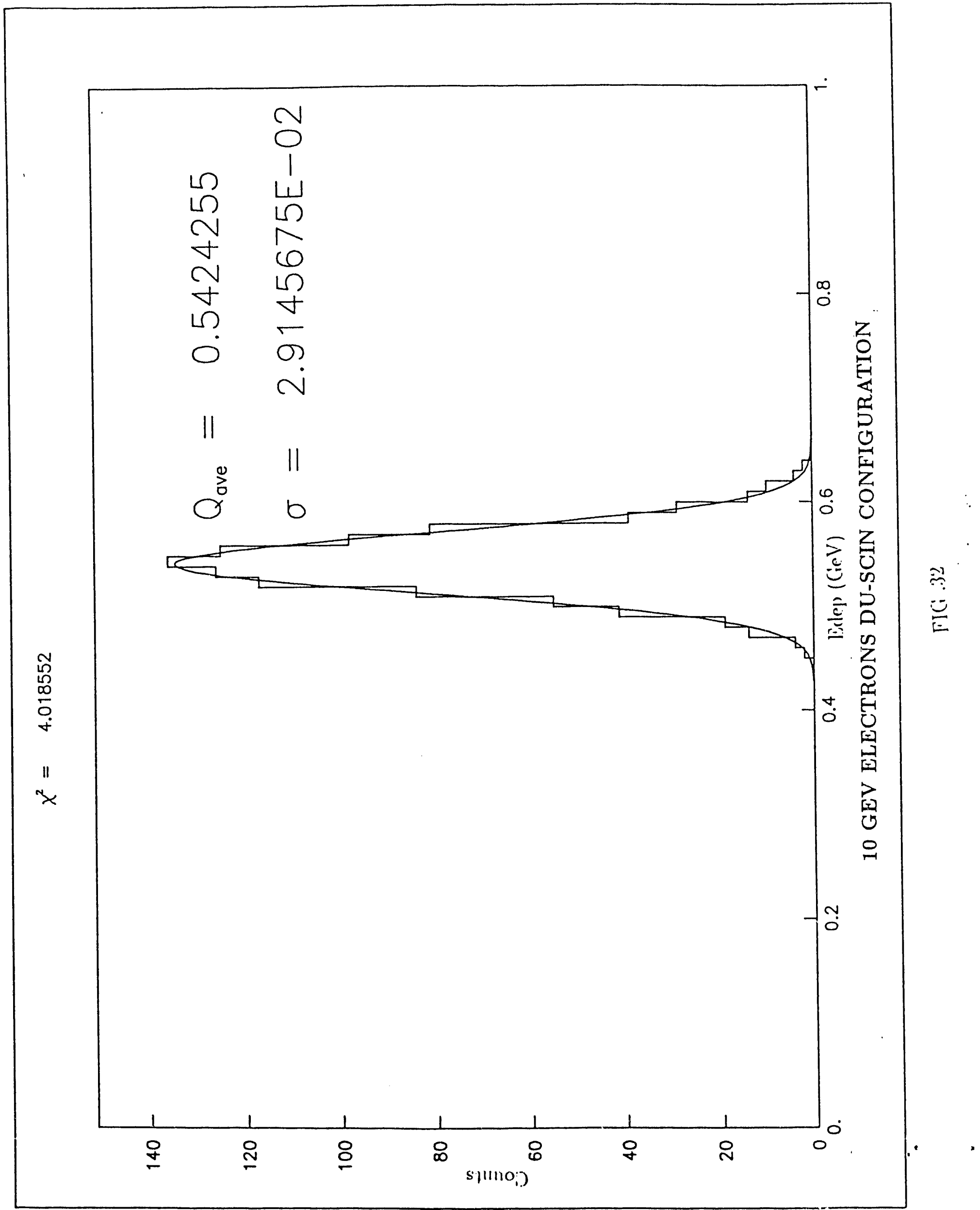




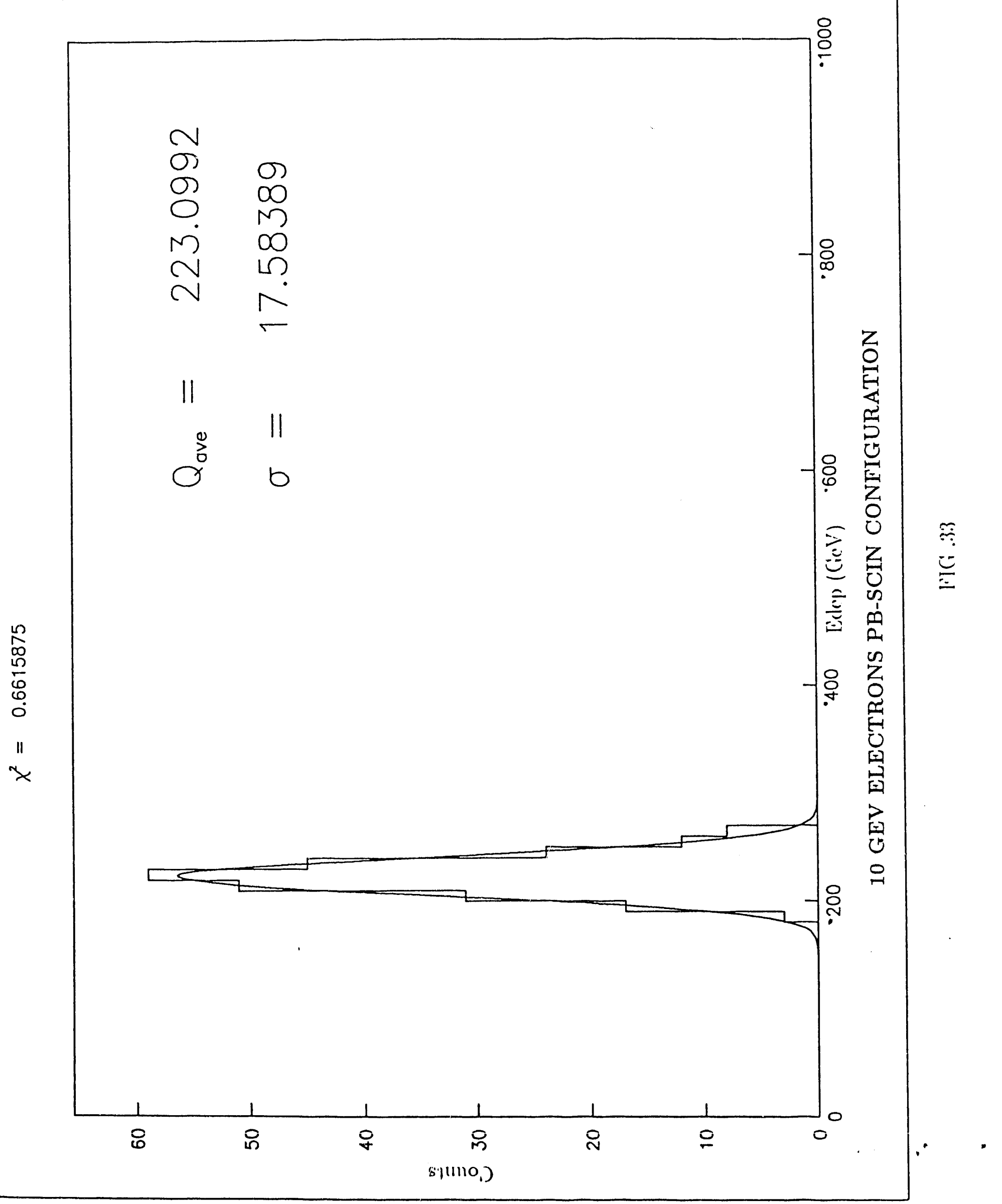




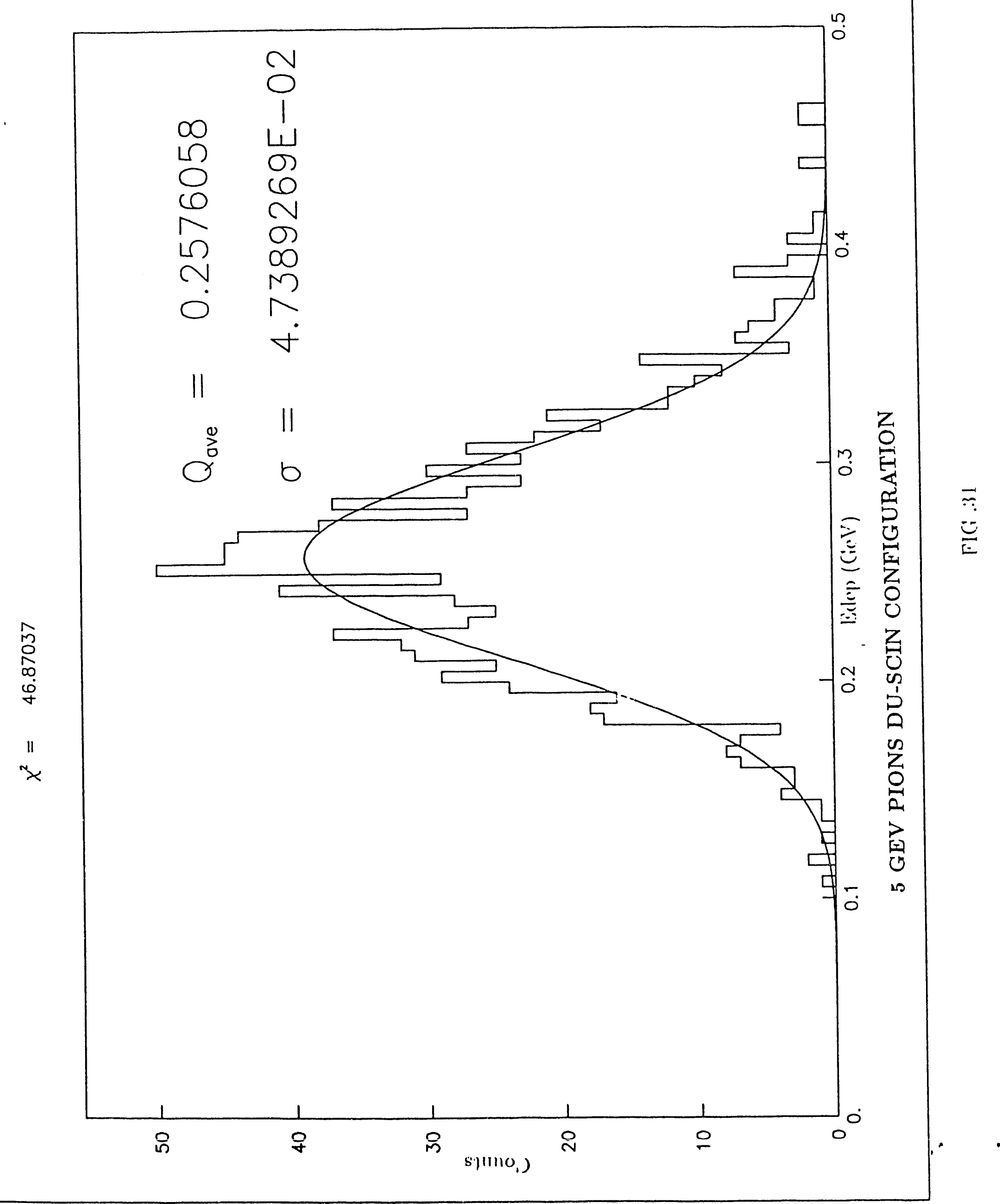




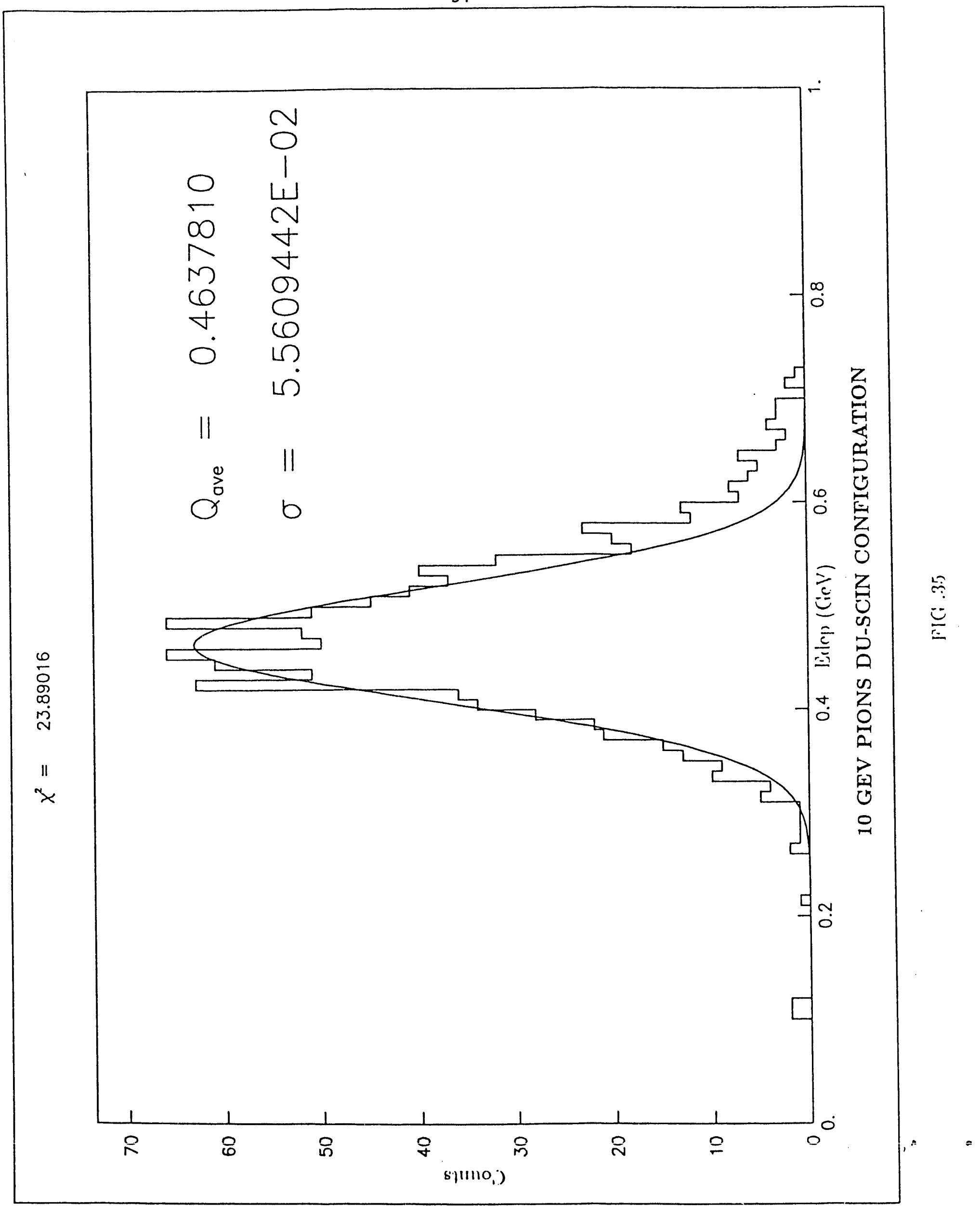




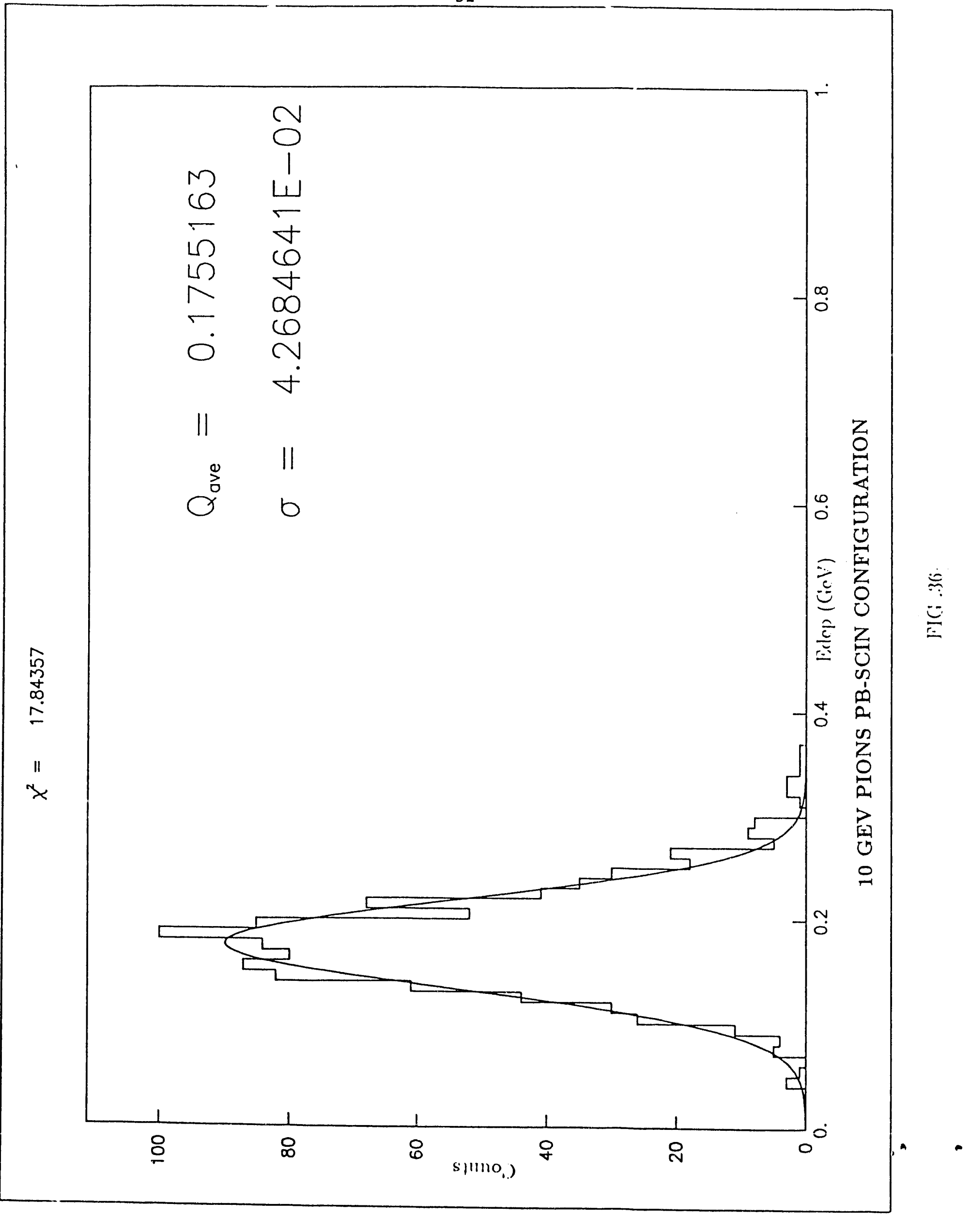




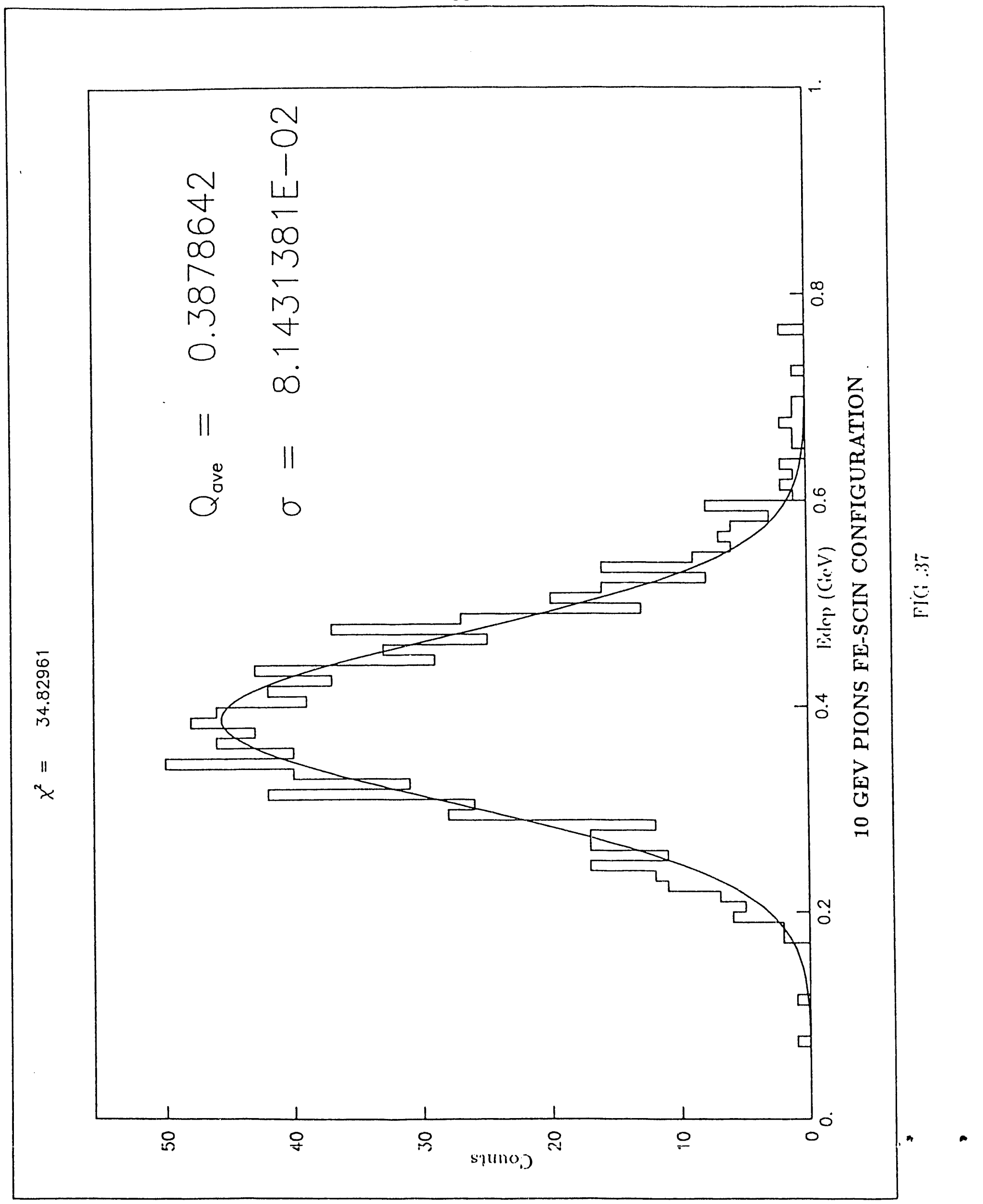




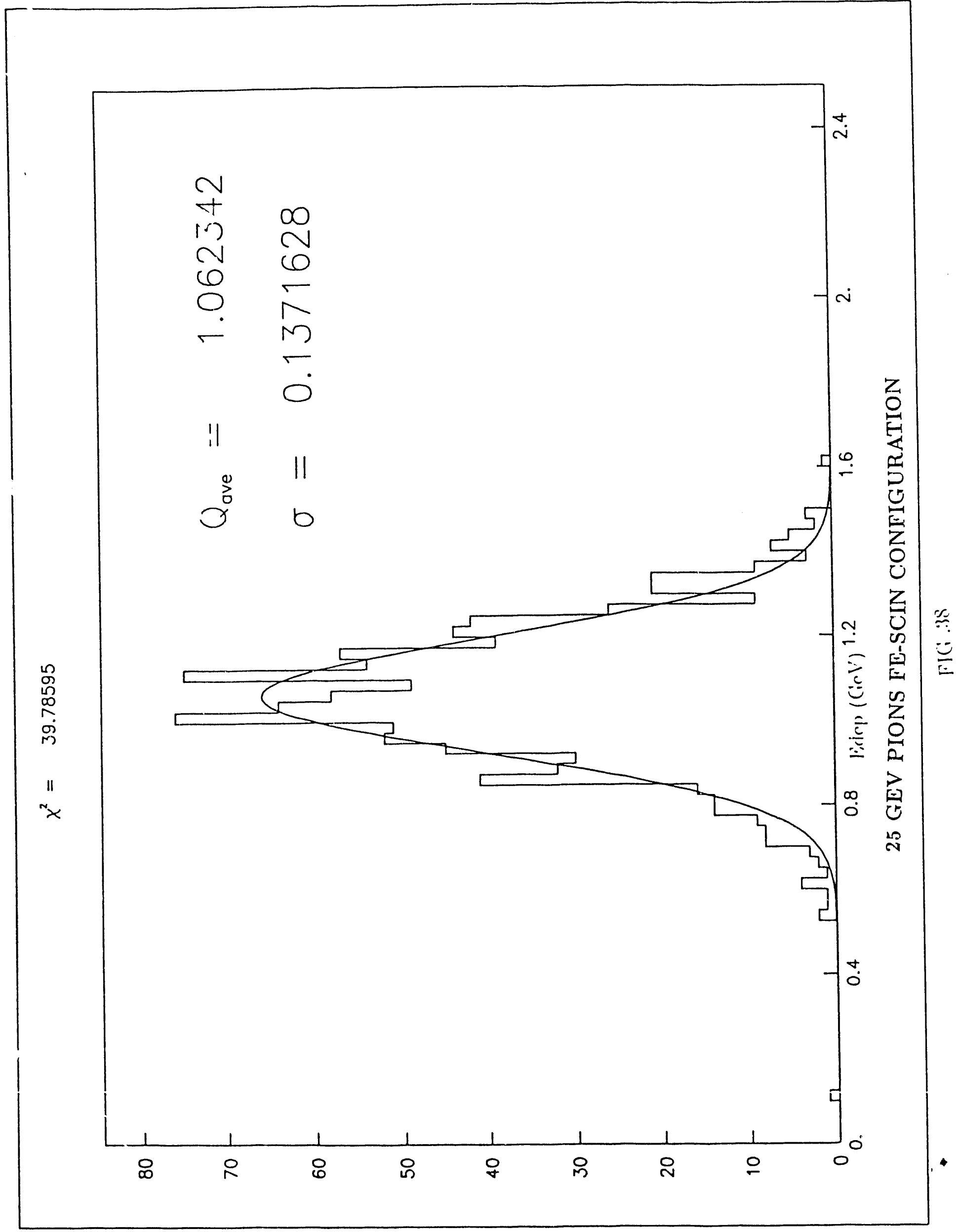



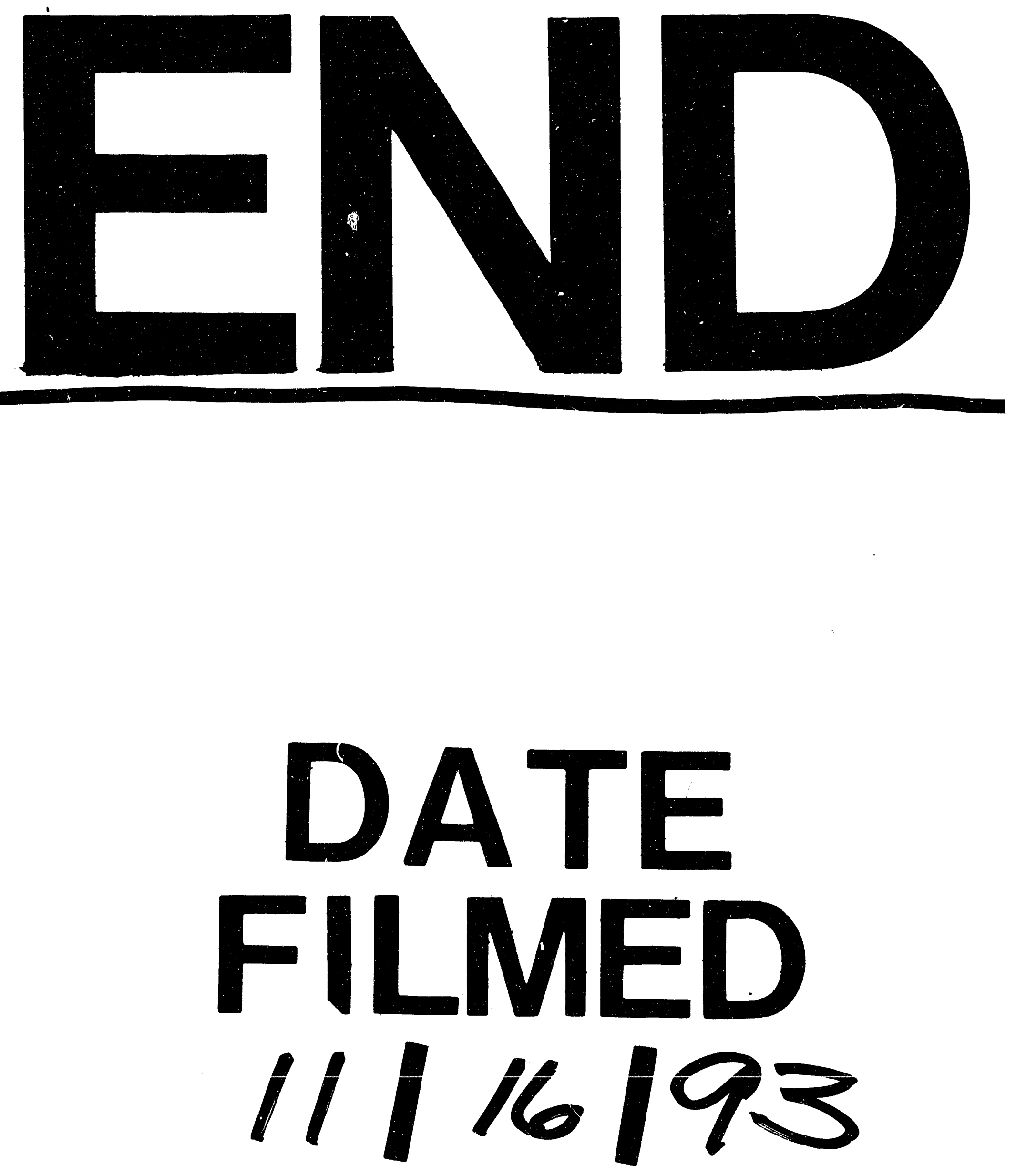

$=$ 
1 